\title{
Meso-Scale Modeling of Irradiated Concrete in Test Reactor
}

\author{
A. Giorla ${ }^{a}$, M. Vaitováb, Y. Le Pape ${ }^{a *}$, P. Štemberk ${ }^{b}$ \\ ${ }^{a}$ Oak Ridge National Laboratory, One Bethel Valley Road, Oak Ridge, TN 37831, USA \\ ${ }^{b}$ Czech Technical University, Thakurova 7, 16629 Praha 6, Czech Republic
}

\begin{abstract}
A numerical model accounting for the effects of neutron irradiation on concrete at the mesoscale is detailed in this paper. Irradiation experiments in test reactor (Elleuch et al., 1972), i.e., in accelerated conditions, are simulated. Concrete is considered as a two-phase material made of elastic inclusions (aggregate) subjected to thermal and irradiation-induced swelling and embedded in a cementitious matrix subjected to shrinkage and thermal expansion. The role of the hardened cement paste in the post-peak regime (brittle-ductile transition with decreasing loading rate), and creep effects are investigated. Radiation-induced volumetric expansion (RIVE) of the aggregate cause the development and propagation of damage around the aggregate which further develops in bridging cracks across the hardened cement paste between the individual aggregate particles. The development of damage is aggravated when shrinkage occurs simultaneously with RIVE during the irradiation experiment. The post-irradiation expansion derived from the simulation is well correlated with the experimental data and, the obtained damage levels are
\end{abstract}

\footnotetext{
${ }^{*}$ Corresponding author: lepapeym@ornl.gov (Y. Le Pape)
} 
fully consistant with previous estimations based on a micromechanical interpretation of the experimental post-irradiation elastic properties (Le Pape et al., 2015). The proposed modeling opens new perpectives for the interpretation of test reactor experiments in regards to the actual operation of light water reactors. 


\title{
Meso-Scale Modeling of Irradiated Concrete in Test Reactor
}

\author{
A. Giorla ${ }^{a}$, M. Vaitováb, Y. Le Pape ${ }^{a *}$, P. Štemberk ${ }^{\mathrm{b}}$ \\ a Oak Ridge National Laboratory, One Bethel Valley Road, Oak Ridge, TN 37831, USA \\ ${ }^{b}$ Czech Technical University, Thakurova 7, 16629 Praha 6, Czech Republic
}

Keywords: irradiation, concrete, numerical model, meso-scale, neutron, swelling, damage

\footnotetext{
*Corresponding author: lepapeym@ornl.gov (Y. Le Pape)
} 


\title{
Meso-Scale Modeling of Irradiated Concrete in Test Reactor
}

\author{
A. Giorla ${ }^{a}$, M. Vaitováb, Y. Le Pape ${ }^{a *}$, P. Štemberk ${ }^{b}$ \\ ${ }^{a}$ Oak Ridge National Laboratory, One Bethel Valley Road, Oak Ridge, TN 37831, USA \\ ${ }^{b}$ Czech Technical University, Thakurova 7, 16629 Praha 6, Czech Republic
}

\begin{abstract}
A numerical model accounting for the effects of neutron irradiation on concrete at the mesoscale is detailed in this paper. Irradiation experiments in test reactor (Elleuch et al., 1972), i.e., in accelerated conditions, are simulated. Concrete is considered as a two-phase material made of elastic inclusions (aggregate) subjected to thermal and irradiation-induced swelling and embedded in a cementitious matrix subjected to shrinkage and thermal expansion. The role of the hardened cement paste in the post-peak regime (brittle-ductile transition with decreasing loading rate), and creep effects are investigated. Radiation-induced volumetric expansion (RIVE) of the aggregate cause the development and propagation of damage around the aggregate which further develops in bridging cracks across the hardened cement paste between the individual aggregate particles. The development of damage is aggravated when shrinkage occurs simultaneously with RIVE during the irradiation experiment. The post-irradiation expansion derived from the simulation is well correlated with the experimental data and, the obtained damage levels are
\end{abstract}

\footnotetext{
${ }^{*}$ Corresponding author: lepapeym@ornl.gov (Y. Le Pape)
} 
fully consistant with previous estimations based on a micromechanical interpretation of the experimental post-irradiation elastic properties (Le Pape et al., 2015). The proposed modeling opens new perpectives for the interpretation of test reactor experiments in regards to the actual operation of light water reactors. 


\title{
Meso-Scale Modeling of Irradiated Concrete in Test Reactor
}

\author{
A. Giorla ${ }^{a}$, M. Vaitováb, Y. Le Pape ${ }^{a *}$, P. Štemberk ${ }^{\mathrm{b}}$ \\ ${ }^{a}$ Oak Ridge National Laboratory, One Bethel Valley Road, Oak Ridge, TN 37831, USA \\ ${ }^{b}$ Czech Technical University, Thakurova 7, 16629 Praha 6, Czech Republic
}

Keywords: irradiation, concrete, numerical model, meso-scale, neutron, swelling, damage

column

\section{Introduction}

The on-going license renewals and the perspective of extended operations of in-service commercial nuclear power plants up to 80 years have brought a new focus on the potential degradation mechanisms affecting concrete structures in the nuclear industry. In particular, the study of the effects of irradiation on concrete appears to have been mostly disregarded since the mid-eighties after two decades of active research, primarily oriented toward the characterization of irradiated concrete mechanical properties - See (Hilsdorf et al., 1978; Fillmore, 2004; Brandt and Jóźwiak-Niedźwiedzka, 2013; William et al., 2013; Field et al., 2015) for comprehensive literature reviews. Significant gaps of knowledge have been reported (Graves et al., 2014), and a renewed interest on this subject has been observed recently (Fujiwara et al.,

\footnotetext{
*Corresponding author: lepapeym@ornl.gov (Y. Le Pape)
} 
2009; Pomaro et al., 2011; Maruyama et al., 2012; Kontani et al., 2013; Rosseel et al., 2014; Field et al., 2015; Le Pape et al., 2015). In particular, the comprehensive database assembled by Field et al. (2015) (307 compression strength data, 62 tensile strength data, 138 elastic modulus data and 114 linear expansion data collected from reactor testing in the open literature) strengthens Hilsdorf et al.'s observations and sheds a new light on the effects of neutron irradiation on concrete: Concrete irradiated with neutrons can see a marked decrease in compressive strength, tensile strength and elastic modulus, particularly at fluence levels above $1.0 \times 10^{+19}$ n.cm ${ }^{-2}$. Neutron irradiation of concrete has a greater impact on the tensile strength than on the compressive strength or the elastic modulus. Loss of tensile strength occurs at fluence levels similar to those for compressive strength, but a $75 \%$ loss of tensile strength can occur compared to a $50 \%$ loss of compressive strength. "The decrease in mechanical properties is attributed to many factors but indications show that the radiation-induced volumetric expansion (RIVE) is a first-order mechanism for loss of mechanical properties under neutron irradiation. Radiation tolerance is expected to be dependent on the aggregate type and a partitioning scheme for evaluating the data was presented. Data suggest siliceous aggregates present the highest risk for deleterious effects of both irradiation and elevated temperatures on concrete due to its susceptibility for low fluence amorphization and corresponding swelling and high thermal expansion coefficients" (Field et al., 2015).

However, it should be recognized that the interpretation of data obtained in test reactor remains problematic in terms of direct application to light water reactors (LWRs) conditions, because: (1) The temperature and irradi- 
ation exposure can be significantly higher in test reactors. (2) Several timedependent mechanisms can occur at different characteristic times whether the irradiation exposure is accelerated in a test reactor during or develops over the course of several decades of operation. Several factors control the transposition of the materials properties and induced expansion obtained in test reactors to LWRs operational conditions:

(1) Temperature: It typically varies from $45^{\circ} \mathrm{C}\left(115^{\circ} \mathrm{F}\right)$ to about $250^{\circ} \mathrm{C}$ $\left(480^{\circ} \mathrm{F}\right)$ in test reactors while the temperature is limited by design to around $65^{\circ} \mathrm{C}\left(150^{\circ} \mathrm{F}\right)$ for LWRs. Temperatures above $\approx 100^{\circ} \mathrm{C}\left(220^{\circ} \mathrm{F}\right)$ result in degradation on cement hydrates and modification of concrete properties - See Naus (2005) for a comprehensive review. The temperature affects the kinetics of moisture transport (Baggio et al., 1995; Bary et al., 2008; de Morais et al., 2009), the amplitude of thermal expansions (Vodák et al., 2004), and the kinetics of shrinkage and creep in the cement paste (Maréchal, 1969). Also, the radiation-induced amorphization of ceramics is controlled by a critical temperature above which full amorphization cannot be reached (Zinkle, 2012). The rate of RIVE for $\alpha$-quartz is increased when the irradiation temperatures decrease (Bylov et al., 1981).

(2) Moisture content: Actual relative humidity conditions are difficult to assess both in test reactors, and in commercial reactors, since no measurements are currently available. The relatively high columntemperature in the reactor cavity and, the potentially elevated temperature in LWRs accelerate concrete drying. On top of that, many experiments are conducted on pre-dried samples to mitigate radiolysis-induced hydrogen production. Hence significant variations of concrete moisture content must be expected. Change 
in moisture content affects concrete strength and elastic modulus (Maruyama et al., 2014b) as well as the amplitude and kinetics of shrinkage and creep (Wittmann, 1970).

(3) Gamma irradiation: Gamma irradiation dose rate and total dose in LWRs at 80 years of operation are estimated respectively around 5 to 20 $\mathrm{kGy} \mathrm{h}^{-1}$, and, 50 to 200 MGy (Kontani et al., 2010; Remec, 2013). Most gamma irradiation experiments reported in the literature (typically using ${ }^{60}$ Co sources) were conducted at lower doses or dose rates than those estimated for LWRs (McDowall, 1971; Soo and Milian, 1989; Sopko et al., 2004; Vodák et al., 2011; Bouniol et al., 2013; Kontani et al., 2013). Notable exceptions are (Kelly et al., 1969; Lowinska-Kluge and Piszora, 2008) reporting gamma exposure conditions similar to LWRs although the temperature was maintained at $20^{\circ} \mathrm{C}$ during the experiments. In test reactors, i.e., combining neutron and gamma irradiations, gamma heating ranges from 0.04 to 1.3 $\mathrm{Wg}^{-1}$, where the estimated gamma heating at the surface of the concrete biological shield (CBS) is only about $0.02 \mathrm{~W} \mathrm{~kg}^{-1}$, i.e., 3 to 5 orders of magnitude lower Remec (2013). Gamma irradiation results in water hydrolysis, the formation of gas pressure (primarily hydrogen and oxygen) (Bibler, 1978; Bouniol and Aspart, 1998), and seems to affect concrete shrinkage and creep (McDowall, 1971).

(4) Neutron irradiation: Fast and thermal neutron fluxes in test reactors varies typically from $5.0 \times 10^{+11}$ to $2.0 \times 10^{+14} \mathrm{n} . \mathrm{cm}^{-2} \mathrm{~s}^{-1}$, and, $3.0 \times 10^{+12}$ to $1.0 \times 10^{+15}$ n.cm ${ }^{-2} \mathrm{~s}^{-1}$, respectively (Maruyama et al., 2013). Remec (2013) estimated the neutron flux at the surface of concrete in prototypical 2-loop and 3-loop pressurized water reactors was about $1.0 \times 10^{+10}$ to $2.0 \times$ 
$10^{+10}$ n.cm ${ }^{-2} \mathrm{~s}^{-1}$, for energies greater than $0.1 \mathrm{MeV}$ and, $2.0 \times 10^{+9}$ to $5.0 \times$ $10^{+9}$ n.cm ${ }^{-2} \mathrm{~s}^{-1}$, for energies lower than $0.41 \mathrm{MeV}$. Hence, there are several orders of magnitude difference in terms on flux exposure. The energy spectra can also vary significantly from the typical spectrum of LWRs. Preliminary theoretical studies by Remec (2014) suggest that $\approx 95 \%$ of the total damage (displacement per atom equivalent) on simple crystalline forms results from fast neutrons above $0.1 \mathrm{MeV}$.

Hence, the effects of irradiation on concrete are the results of a complex history and mechanisms involving multiple, potentially coupled, factors which can significantly vary from the test reactors to the actual in-service conditions in LWRs. The approach adopted in this article is to develop an irradiated concrete meso-scale model to interpret the experiments published in the open literature by Elleuch et al. (1972). A first meso-scale model of irradiated concrete was recently developed by Salomoni et al. (2014), but does not account for the predominant effect of RIVE. We have chosen to simulate Elleuch et al.'s irradiation experiments because thorough details are uniquely provided regarding the experimental protocol before and during irradiation as well as the properties of the concrete constituents. However, the concrete is made of high-alumina cement paste and serpentine aggregates, which does not necessarily make it representative of concrete biological shield in typical pressurized water reactor configurations.

\section{Modeling Strategy}

Assuming the theory of homogenization of random media, Le Pape et al. (2015) developed a preliminary micro-mechanical model of irradiated con- 
crete to evaluate the role of aggregate RIVE and its interaction with the cement paste on the development of concrete damage and the macroscopic swelling of irradiated concrete. The inherent limitations of this model are: (1) The difficulty to assess separately the damage induced by aggregate RIVE and the effective elastic modulus of concrete; (2) The difficulty to assess the role of relaxation in the hardened cement paste in the dissipation of the elastic energy developed by aggregate RIVE. Relaxation of RIVE-induced stresses in the cement paste may occur differently depending on the characteristic time of the aggregate swelling kinetics. In other words, the aggregate expansion occurring at a strain rate function of the fluence and the aggregate nature, results in varied stress-relaxation in the surrounding cement paste. In an attempt to overcome these limitations, we use the $\mathrm{C}++$ extended finite element library AMIE (Automated Mechanics Integrated Environment) to simulate the effects of irradiation on concrete at the mesoscale. AMIE was originally developed in the context of modeling alkali-silica reaction (ASR) (Dunant and Scrivener, 2010), but its versatility as well as its in-built random microstructure generator makes it a generic platform to investigate the mechanical behaviour of concrete and heterogeneous materials. The objectoriented architecture allows for an easy implementation of new numerical algorithms or material constitutive laws, for example for creep, damage, or plasticity. AMIE uses space-time finite elements to simulate visco-elastic materials (Giorla et al., 2014). This alternative method to more common finite difference schemes provides a more accurate representation of microstructures which change in time, and a robust framework to solve coupled creep-damage problems (Giorla et al., 2015). 
The simulations are performed on two-dimensional slices (here, plane strain hypothesis) of the material microstructure to be able to characterize the entire particle size distribution of the aggregates. Indeed, the smallest aggregates have a critical impact on the simulated fracture properties of heterogeneous materials (Dupray et al., 2009), and their explicit representation in a 3D simulation would be impractical, both in terms of memory and computational time. However, two-dimensional simulations cannot fully capture a certain number of geometrical effects, such as the possible overestimation of crack bridging in the cement matrix, an effect which could lead to an early failure of the sample, as found in ASR simulations (Dunant and Scrivener, 2012). The simulations were carried out on a set of dedicated workstations. Each simulation took an average of 20 hours to complete.

\subsection{Microstructure Generation}

We reproduce as close as possible the conditions in which the samples were cast in order to obtain representative microstructures. First, we generate a list of aggregates according to a Fuller and Thompson's particle size distribution (1907) calibrated to represent the different aggregate classes (sand, gravel, coarse) given in the experimental mix design. Aggregates are defined as circles, neglecting effects of segregation or casting direction. The generated particles are randomly placed in the sample, with a minimum inter-distance of $0.1 \mathrm{~mm}$. Using polygonal aggregates would have no significant effect on the visco-elastic response of the material (Lavergne et al., 2015), but would make the sample more brittle depending on the aspect ratio of the particles (Du and Sun, 2007). As the geometry of the aggregates used in Elleuch et al. experiments is unknown, this effect is ignored to limit the parameters of the 
model.

The largest aggregate diameter is of $12 \mathrm{~mm}$, which is almost half the width of the sample. In these conditions, the sample may not be entirely representative of the concrete, and the random placement would induce a scatter in the simulated results. The variability of the results with different initial positions of the aggregates is assessed in the discussion of this paper. Unless specified, the position of the aggregates is kept the same from one simulation to another to avoid such random scatter.

It is assumed that the aggregate is homogeneous. It is likely that these are actually polyphasic materials in which each mineral would exhibit different swelling behavior under irradiation. This might cause internal stresses and cracking within the individual aggregate particles (as it is the case for some aggregates subject to ASR), which in turn has a significant impact on the simulation results. However, this effect would require an understanding of the behavior of each particular phase, as well as a good representation of the aggregate microstructure. In absence of relevant data at this point, this effect is neglected.

\subsection{Mesh Generation}

The microstructure is discretized with a conforming mesh composed of triangular linear elements. The calculations in this paper were carried out on a mesh with $\approx 12,000$ elements for a $2.5 \times 2.5 \mathrm{~cm}$ sample. The mesh is generated with a Delaunay triangulation so that the node density remains homogeneous across the sample. This is achieved by removing points in the cement paste which are too close to the aggregate particles, and ignoring those aggregate particles with a radius smaller than the characteristic size 
of the finite elements. After removal of the smallest particles, the elements representing the aggregates in the mesh cover $51 \%$ of the surface of the sample against the $66 \%$ in the mix design from the Elleuch et al. experiment. It is therefore expected that a lower expansion in the simulation than in the experiments will occur. The microstructure, mesh and boundary conditions are represented in Figure 1.

Figure 1: Finite element mesh and boundary conditions. Aggregate elements are represented in black, cement paste in gray.

\section{Constitutive Laws}

Irradiated concrete is simulated at the mesoscale with a finite element representation of the microstructure. The material properties and behavior of an element in the mesh depend on whether that element is located in the cement paste or in the aggregate.

The proposed model aims at calculating the mechanical effects of combined irradiation, temperature, and relative humidity: overall expansion and mechanical damage. However, the transport processes are not accounted for, which limits the analysis to uniform fields for the neutron fluence, temperature, and relative humidity.

In the following, mechanical properties are considered functions of the

neutron fluence $\Phi$, the temperature $T$, and the relative humidity $h$. The 
subscript ${ }_{p}$ denotes the material properties of the cement paste, $a$ of the aggregate.

The different material parameters and their value are listed in Table 2.

\subsection{Hardened Cement Paste}

The strain $\epsilon$ of a cement paste element is decomposed into the sum of the elastic strain $\epsilon_{0}$, the recoverable and non-recoverable creep strains $\epsilon_{r}$ and $\epsilon_{c}$, the thermal expansion $\epsilon_{T}$, and the drying shrinkage $\epsilon_{h}$.

Elastic deformations. The elastic strain is calculated with:

$$
\sigma=(1-d) \mathbb{C}_{p}: \epsilon_{0}
$$

where $\mathbb{C}_{p}$ is the material fourth-order elastic tensor and $d$ an isotropic damage variable in the sense of continuum damage mechanics (see for example Jirásek (2004)). We assume the cement paste is mature, i.e., fully hardened once chemical hydration is completed. Using plane strain assumption, $\mathbb{C}_{p}$ can be expressed from the Young modulus $E_{p}$ and Poisson ratio $\nu_{p}:$

$$
\mathbb{C}_{p}=\frac{E_{p}}{\left(1+\nu_{p}\right)\left(1-2 \nu_{p}\right)}\left[\begin{array}{ccc}
1-\nu_{p} & \nu_{p} & 0 \\
\nu_{p} & 1-\nu_{p} & 0 \\
0 & 0 & 1-2 \nu_{p}
\end{array}\right]
$$

The Young modulus of the cement paste depends strongly on the temperature (Naus, 2010) and the relative humidity (Wittmann, 1973) in the sample. This effect is characterized in the proposed model by adjusting $E_{p}$ as a function of the maximum temperature reached in the sample at any given instant $\max (T)$ : 


$$
E_{p}(T)= \begin{cases}E_{p}\left(T=T_{0}\right), & T<T_{1} \\ \left(1-d_{T} \times \frac{\max (T)-T_{1}}{T_{\max }-T_{1}}\right) E_{p}\left(T=T_{0}\right), & T \geq T_{1}\end{cases}
$$

where $T_{0}$ is the reference temperature at which the Young modulus was measured, $T_{1}$ a threshold temperature below which no thermal damage occurs, and $d_{T}$ is the loss of elastic properties between the reference temperatures $T_{1}$ and $T_{\max }$.

Thermal expansion. The thermal expansion is linear with the temperature: $\epsilon_{T}=\alpha_{p}\left(T-T_{0}\right)$ where $\alpha_{p}$ is the coefficient of thermal expansion and $T_{0}$ the reference temperature. In cementitious materials $\alpha_{p}$ is a function of the amount of water in the material (Grasley and Lange, 2007), but this effect is ignored in the proposed model by lack of better data.

Creep deformation. There is very limited data on creep of irradiated concrete available in the literature. McDowall (1971) conducted sealed shrinkage and uniaxial creep $\left(10 \mathrm{MPa}\right.$ at $\left.30^{\circ} \mathrm{C}\right)$ experiments on concrete under gamma irradiation while control samples were tested in similar temperature condition. Venting of irradiation induced gases, i.e., induced water radiolysis, is accomplished by means of a gas bubbler filled with water to prevent vapor migration. The shrinkage measured during irradiation was more than twice of that of the control sample, while the creep curve under irradiation increasingly diverged from the control sample. After 250 days of loading, the irradiated creep amplitude was about $70 \%$ of that of the control sample. Separating the effect of loss of moisture from potential intrinsic effects of the gamma-irradiation is difficult because the gas release was not measured. Creep amplitude of pre-dried cement paste samples decreases as the internal 
relative humidity diminishes (Wittmann, 1970). However, it must also be noted that only gas transport seems to be permitted in McDowall's experiment while "normal" moisture transport and subsequent internal drying in concrete is governed primarily by vapor diffusion and liquid permeation (the role of gas transport is usually neglected because the internal gas pressure is assumed close to the atmospheric pressure in a open system (Mainguy et al., 2001)). Hence, limited loss of moisture content could have occurred. The possibility of an actual effect of gamma-irradiation on creep mechanism cannot be ruled out, but, by lack of sufficient experimental data, the potential effect of gamma-irradiation on shrinkage and creep properties are disregarded in the proposed modeling.

However, modeling of the cement paste creep under the effects of moisture content and temperature is considered here because of the it potential impact on the development and propagation of cracks in the cement paste. In particular, it seems important to consider creep in the perspective of modeling the concrete biological shield (CBS) to account for any RIVE rate effect.

Several studies have shown that the long-term creep of cementitious materials follows a logarithmic curve, from the short-term and nanoscale Vandamme and Ulm (2009) to the long-term and macroscale (Ulm et al., 1999; Bengougam, 2002; Bažant et al., 2012). This logarithmic trend can also be understood from a micro-mechanical perspective by the propagation of viscous interfaces at the nanoscale, for example arising from the opening of diffused micro-cracks in the hydrates microstructure (Shahidi et al., 2014). From a modelling perspective, this long-term creep can be represented by a time-dependent dashpot as in the B3 model (Bažant and Baweja, 2000): 


$$
\sigma=(1-d)\left(1+\frac{t}{\tau_{p}}\right) \mathbb{E}_{p}: \dot{\epsilon}_{c}
$$

where $\mathbb{E}_{p}$ is a fourth-order viscosity tensor, $\tau_{p}$ is a material characteristic time, $d$ the damage variable, $\epsilon_{c}$ is the long-term creep strain, and the overdot is the time-derivative operator. $\mathbb{E}_{p}$ can be calculated from the uni-axial viscosity of the material $\eta_{p}$ and the Poisson ratio $\nu_{p}$ using the plane strain approximation. In the proposed model, the same Poisson ratio for the elastic and visco-elastic deformations is used:

$$
\mathbb{E}_{p}=\frac{\eta_{p}}{\left(1+\nu_{p}\right)\left(1-2 \nu_{p}\right)}\left[\begin{array}{ccc}
1-\nu_{p} & \nu_{p} & 0 \\
\nu_{p} & 1-\nu_{p} & 0 \\
0 & 0 & 1-2 \nu_{p}
\end{array}\right]
$$

This behavior represents well the long-term creep of the material, but the deformations it induces cannot be recovered upon unloading. A single Kelvin-Voigt unit is therefore added in series to the dashpot described above:

$$
\sigma=(1-d) \mathbb{E}_{p}:\left(\frac{1}{\tau_{p}} \epsilon_{r}+\dot{\epsilon}_{r}\right)
$$

where $\epsilon_{r}$ the recoverable creep strain. The total creep strain is therefore the sum of the recoverable and non-recoverable strains, i.e., respectively $\epsilon_{r}$ and $\epsilon_{c}$ (Neville, 1960).

In the present model, the same viscosity tensor for the Kelvin-Voigt and the dashpot is assumed. This hypothesis is based on the observation that the recoverable and non-recoverable parts of the deformation cannot be distinguished on an experimental creep curve. A better approximation would be obtained if the unloading behaviour of the cement paste is known from the 
experiments (Hilaire et al., 2014). The final rheological model for the creep of the cement paste is shown in Figure 2.

Figure 2: Rheological model of the hardened cement paste.

The effect of temperature, relative humidity, and irradiation on creep can be captured by adjusting the viscosity $\eta_{p}$ and/or characteristic time $\tau_{p}$.

The effect of temperature on acceleration of creep (Maréchal, 1969; Bengougam, 2002) is represented in the model with an Arrhenius law:

$$
\tau_{p}(T)=\exp \left[T_{a c t}\left(\frac{1}{T}-\frac{1}{T_{0}}\right)\right] \tau_{p}\left(T=T_{0}\right)
$$

where $T_{0}$ is the reference temperature at which the creep properties were measured. $T_{a c t}$ is an "activation temperature" for creep. The value of $T_{a c t}$ varies from one cement composition to another: the B3 model for concrete suggests to use a value of 5.000 K (Bažant and Baweja, 2000), but Bengougam (2002) found values ranging from 6.000 to $17.000 \mathrm{~K}$ for cores extracted from concrete dams. In the current simulations, we use $5.000 \mathrm{~K}$ as suggested by Bažant and Baweja.

At constant relative humidity, the creep of the cement paste decreases with a lower water content (Wittmann, 1970). From the careful analysis of the experiments of Wittmann, who studied the creep of sealed cement paste specimens, pre-dried at varied relative humidities, the creep viscosity $\eta_{p}$ and the relative humidity $h$ can be related: 


$$
\eta_{p}(h)=\left[\frac{1-h}{h_{c}}+\exp \left(-\frac{1-h}{h_{c}}\right)\right] \eta_{p}(h=1)
$$

Where $h_{c}$ is a material property (same dimension as a relative humidity) found to be equal to $\approx 0.2$ in the case of Wittmann's experiment, although it might vary from one cement formulation to another. With this formulation, the material will still exhibit creep deformation, even at very low relative humidity.

It should also be noted that the reduction of the creep with the relative humidity is different from the Pickett effect (i.e., the increase of the apparent creep of a specimen in drying conditions) (Pickett, 1942), primarily caused by microcracks induced by gradients in relative humidity through the sample (Benboudjema et al., 2005). In other words, the Pickett effect can be considered as a structural effect on the heterogeneous micro-structure of concrete, and is therefore omitted in the present material constitutive behavior formulation at the meso-scale.

Drying shrinkage. As the result of relatively high temperature and irradiation heating, loss-of-water-induced shrinkage is observed during post-irradiation evaluation of test reactor experiments — See (Field et al., 2015, Fig. 6) for details. Drying shrinkage in cementitious materials is usually simulated as a function of the total water content in the material (Baroghel-Bouny et al., 1999). However, this requires the characterization of the adsorption/desorption curves of the material. This information is not available in open literature publications dealing with irradiated concrete. The alternative is to use the relative humidity as in the B3 model (Bažant and Baweja, 2000). Unfortunately, neither the moisture content or the relative humidity 
are measured during irradiation experiments available in the literature.

In the present model, the drying shrinkage is decomposed into two separate terms: firstly, assumed to be linear with the relative humidity $(\mathrm{RH})(h)$ before irradiation, and secondly, linear with the neutron fluence $(\Phi)$, which is more commonly measured in irradiation experiments, and thus can be calibrated directly with experimental data:

$$
\epsilon_{h}=k_{h}\left(h-h_{0}\right)+k_{\Phi} \Phi
$$

with $k_{h}$ is the non-irradiated drying coefficient of the material, $h_{0}$ the reference relative humidity before the experiment, and $k_{\Phi}$ the irradiated drying coefficient.

Strength and Stress-Strain Behavior. Cement paste is considered as a quasibrittle material with a linear softening branch. This behavior is characterized by the tensile strength $f_{t}$ and the ultimate tensile strain at the end of the softening curve $\epsilon_{y, t}$ (respectively $f_{c}$ and $\epsilon_{y, c}$ for the failure in compression).

Damage is simulated with an algorithm adapted from the work of Rots and Invernizzi (2004) and Dunant and Bentz (2015) for time-dependent materials. The damage, $d$, in a given element, is increased by $\Delta d$ when the strain reaches the failure surface of the material. This instant is determined for any single element as the root of:

$$
\|\bar{\epsilon}\|-\frac{E_{\text {soft }}}{E_{\text {soft }}+E_{\text {inst }}} \epsilon_{y, t}=0
$$

where $\|\bar{\epsilon}\|$ is the maximum principal component of the nonlocal strain in the element, $E_{\text {soft }}$ the softening modulus (i.e., the slope of the softening 
branch), and $E_{\text {inst }}$ the apparent instantaneous modulus, accounting for the current damage and visco-elastic strains. With this algorithm, elements are damaged in a sequence of damage events. The key point of the algorithm is that the instant at which these events occur are explicitly known from the space-time approximation. The time-step can then be adjusted to account for the period between two damage instants during which the material behaves linearly. The viscoelastic strains are thus exactly integrated over that time period, without further modification of the visco-damage model or finite element procedure. The entire algorithm is described in greater details in Giorla (2013). The strains are smeared over a certain radius $r_{n l}$ to avoid localization of the damage in a single band of elements (Pijaudier-Cabot and Bazant, 1987).

The strength of the material is, furthermore, dependent on the strain rate, the temperature and the relative humidity. The strength of concrete is higher for faster strain rates (Rusch, 1960), but the failure mode also changes from brittle to ductile when the strain rate is slower. Bažant and Gettu (1992) quantified this effect on concrete loaded at different strain rates, but not on cement paste, because of the difficulty to measure post-peak behavior on cementitious samples. The transition between failure modes may lead to important differences in the stability of the fracture propagation, as observed from meso-scale simulation of ASR (Giorla et al., 2015). However, this effect is ignored in the proposed model due to the lack of relevant data for cement paste.

At high temperature, the strength of the cement paste decreases first because of the dilation and evaporation of the pore water, then reaches a 
minimum around $120^{\circ} \mathrm{C}$, after which it increases and plateaus up to approximately $450^{\circ} \mathrm{C}$ (Komonen and Penttala, 2003). At the minimum (for temperatures between 100 to $200^{\circ} \mathrm{C}$, depending on the material), the loss of compressive strength is approximately equal to $25 \%$, while the loss of tensile strength can reach up to $80 \%$ of the material initial strength.

The strength of the cement paste is also strongly dependent on the amount of water present in the microstructure. Maruyama et al. (2014a) found a complex evolution of the strength with the relative humidity: the strength first increases, then decreases until it reaches its original value (around $40 \%$ relative humidity), then increases again.

Radiation experiments on pure cement paste have shown that the loss of strength in the paste is primarily caused by the high temperature or the loss of water during the experiment (Kelly et al., 1969; Elleuch et al., 1972). The separate effect of radiation on the strength of cement paste is therefore neglected in the model.

Simulating the influence of temperature and relative humidity on the strength of the material would introduce a large number of new material parameters which are generally not evaluated for the cement pastes used in the radiation experiments, and are likely to be strongly dependent on the cement type and composition. Given that the experiments of Elleuch et al. (1972) use a very specific aluminate cement, for which the properties at high temperature or low relative humidity are unknown, these effects are not accounted for in the proposed model. 


\subsection{Aggregate}

The aggregate is simulated as a purely elastic material with an imposed deformation equal to the sum of the thermal expansion $\epsilon_{T}$ and the RIVE $\epsilon_{\Phi}$. The aggregate is considered monophasic with homogeneous mechanical properties (including the RIVE). Under these conditions, the damage initiates and propagates exclusively in the cement paste, so the damage properties of the aggregates are neglected. Based on early simulations, the internal stresses inside the aggregate were found well below the material strength. This hypothesis would not be applicable in the case of polyphasic aggregate, as differential strains could cause cracking inside the individual aggregate particles, as what can be found in some cases for ASR. This has been proposed by Seeberger and Hilsdorf (1982) as a possible mechanism of degradation for irradiated granite.

RIVE of silica-bearing aggregate has been confirmed as a potentially important degradation mechanism (Seeberger and Hilsdorf, 1982; Le Pape et al., 2015; Field et al., 2015) for concrete under neutron irradiation: RIVE can develop important dimensional change, comparable or higher, to those observed for ASR-affected concrete. Neutron exposure, at high fluence, causes amorphization (Bonnet et al., 1994; Douillard and Duraud, 1996) (disordering of the atomic structure) and volumetric change (Wittels, 1957; Primak, 1958; Zubov and Ivanov, 1966; Seeberger and Hilsdorf, 1982) (change of density) of crystalline structures of specific aggregates. Amorphization results in a change of loss of elastic properties (Frondel, 1945; Seeberger and Hilsdorf, 1982). The volumetric change is prominent for quartz, but is not so marked for calcite (Hauser and Schenk, 1964; Luthra, 1969) even at fluence 
reaching $1.0 \times 10^{20}$ n.cm ${ }^{-2}(E>0.1 \mathrm{MeV})$. Other silicates, like zircon and micas (muscovite, biotite), exhibit important density/volume change (Seeberger and Hilsdorf, 1982; Crawford and Wittels, 1956, 1958) under neutron irradiation above $1.0 \times 10^{19} \mathrm{n} . \mathrm{cm}^{-2}$. The integrity of irradiated granite at high fluence is also questioned (Seeberger and Hilsdorf, 1982).

In the present work, we use the sigmoid curve from the work of Zubov and Ivanov (1966) to simulate the RIVE as a function of the fluence:

$$
\epsilon_{\Phi}=\frac{\kappa \epsilon_{\max }\left(e^{\delta \Phi}-1\right)}{\epsilon_{\max }+\kappa e^{\delta \Phi}}
$$

where $\epsilon_{\max }$ is the expansion after complete amorphization, $\kappa$ and $\delta$ control the shape of the curve. These parameters can be identified from the expansion curves of the pure aggregate (Le Pape et al., 2015).

Thermal Expansion of Aggregate. The thermal expansion of aggregate can account for a significant portion of irradiated concrete expansion (Le Pape et al., 2015) when the irradiation experiments are conducted at higher temperature (Elleuch et al., 1972). Besides a few exceptions, Johnson and Parsons (1944); Fei (1995) observed that the thermal expansions of most rocks follows smooth, fairly linear, curves with temperature ranging from $-10^{\circ} \mathrm{C}$ to $100^{\circ} \mathrm{C}$. van Buskirk et al. (1985) observed that the thermal expansion of a sandstone, a tuff, and a basalt was also nearly linear in the range of temperature between $20^{\circ} \mathrm{C}$ to $150-250^{\circ} \mathrm{C}$. 


\section{Experimental Data}

\subsection{Temperature and irradiation scenarios}

The temperature history is described in great details in (Elleuch et al., 1972). Only a few elements are not provided, and thus, require additional assumptions. After fabrication, "The cement paste and concrete molds were placed in water heated at $60^{\circ} \mathrm{C}$ for $24 \mathrm{~h}$ before being stored for curing at $20^{\circ} \mathrm{C}$ and $60 \%$ relative humidity. The thermal treatment improves the stability of the crystalline structure of the aluminate hydrates" (Le Pape et al., 2015). After cooling, the specimens were stored at $20^{\circ} \mathrm{C}$ and $60 \% \mathrm{RH}$ for three months. The second pre-heating, also referred to as thermal treatment reached $250^{\circ} \mathrm{C}$. "The purpose of this curing process was to bring about an initial elimination of water from the samples and to lessen the harmful effects of the sudden temperature rise that the samples have to withstand at the start of irradiation" (Elleuch et al., 1972). There is no information whether the samples were subjected to the highest temperature for the same period of time as at the other stages or not, therefore one week in this case is only an assumption. After the second pre-heating the temperature returned to the room temperature of $20^{\circ} \mathrm{C}$ before irradiation testing. In the simulations, it is assumed that all samples were subjected to the same pre-irradiation temperature scenario.

Elleuch et al. also provide the temperature distribution in the irradiation capsules during the irradiation. The temperature evolution during the irradiation is not known, however, some information can be inferred from a related article (Rappeneau et al., 1966) on concrete testing in the same reactor. The temperature reaches a peak at the end of the first day, after 
which it decreases and stabilizes after 2.5 days. This scenario was compared with a simplified scenario assuming the temperature reaching its base level in approximately one day: both scenarios lead to very similar damage development in the specimen.

The total irradiation fluence received by the concrete specimens, distributed in 5 different capsules, namely G1 to G5, ranges between 1-10 $\times 10^{+19} \mathrm{n} . \mathrm{cm}^{-2}$ (fast neutrons). The question of the actual neutron flux spectrum does not need to be raised here for the interpretation of the irradiation experiments because all materials properties function of the fluence are provided for energies higher than $1.0 \mathrm{MeV}$. For each capsule, three couples of temperature and fluence were simulated in order to cover the wide range of observed variations (see Figure 3) obtained from (Elleuch et al., 1972, Figure 3 and 5, combined and adapted). Specific values are reported in Table 1. The corresponding fluxes range from 2.2 to $4.7 \times 10^{+12}$ n. $\mathrm{cm}^{-2} \mathrm{~s}^{-1}$, i.e., in a slightly wider range of fast neutron flux than that reported by Elleuch et al..

Figure 3: Temperatures and neutron fluences for the different capsules (G1-G5) in Elleuch et al. (1972) experiments. Solid lines represent the lower-bounds, dashed lines the upper bounds.

\subsection{Constitutive parameters}

The parameters of the model presented above were carefully calibrated on experimental data when possible, or using backward numerical analysis 
Table 1: Temperatures and fast neutron fluence $(E>1.0 \mathrm{MeV})$ used in the simulations.

\begin{tabular}{lrr}
\hline Capsule & $\begin{array}{r}\text { Temperature } \\
\left({ }^{\circ} \mathrm{C}\right)\end{array}$ & $\begin{array}{r}\text { Fluence } \\
\left(\times 10^{+19}\right.\end{array}$ \\
\hline n.cm & -2 \\
& 162 & 1.37 \\
& 194 & 1.57 \\
& 205 & 2.62 \\
\hline G2 & 176 & 1.73 \\
& 207 & 2.22 \\
& 224 & 3.79 \\
\hline G3 & 202 & 3.32 \\
& 223 & 5.20 \\
& 235 & 4.10 \\
\hline G4 & 146 & 3.92 \\
& 203 & 4.57 \\
& 204 & 5.39 \\
\hline G5 & 173 & 6.87 \\
& 191 & 9.82 \\
& 223 & 10.12 \\
\hline
\end{tabular}


otherwise. Three different cases were met:

- Parameters that were directly measured by Elleuch et al. were used without modification. Regression analysis using a least-square approximation was used to extract parameters from the experimental curves.

- Experimental data from the literature were used for parameters not given by Elleuch et al., provided they were measured on similar materials. This is for example the case of the creep properties of the cement paste.

- If there were no direct experimental data to calibrate a certain parameter, but where experimental data showed some tendency, the values of these parameters were obtained using backward analysis. Lower and upper bounds were provided when possible to assess the uncertainty on these values.

These three different approaches complement each other and provide a rigorous framework for analysis of experiments in which experimental data are missing. Parameters for which no experimental data was found, and which could not be derived from backward analysis of Elleuch et al. (1972) experiments, were neglected to avoid including further sources of uncertainties.

Elastic properties. The mechanical properties of aggregate and cement paste are given although the modulus of elasticity is described by the ultrasonic wave propagation velocity. Then, the dynamic modulus can be derived by:

$$
V^{2}=\frac{E_{d}(1-\nu)}{\rho(1+\nu)(1-2 \nu)}
$$


where $V$ is the ultrasonic wave propagation velocity, $\rho$ is the material density an $E_{d}$ is the dynamic modulus. The finite element calculation uses the static modulus of elasticity, therefore, the following expression which used to be part of the British code is applied on the cement paste:

$$
E=1.25 E_{d}-19
$$

The static modulus of aggregate is estimated by an empirical formula (Eissa and Kazi, 1988):

$$
\log _{10} E=0.02+0.77 \log _{10}\left(\rho E_{d}\right)
$$

It gives the modulus of elasticity of the cement paste, $35.5 \mathrm{GPa}$, the aggregate, 97.3 GPa and the concrete, 59.1 GPa.

Creep properties. Elleuch et al. did not measure the creep or relaxation properties of their cement paste, so these must be assumed from other sources. The cement used is an aluminous cement, and very limited data concerning creep of aluminous cement or concrete can be found in the literature. Hummel (1959) measured the creep of concrete made with ordinary Portland cement (OPC), in one hand, and aluminous cement, in the other hand. The water-cement ratio and aggregate-cement ratio was equal in both formulations. We fitted the experimental curves from Hummel with the logarithmic creep model described previously (see Eqs 4,6), and found that the viscosity $\eta_{p}$ is equal for OPC and aluminous cements, but the characteristic time of the creep deformation $\tau_{p}$ is higher for the concrete made with aluminous cement paste. The experimental creep curves and corresponding fits are shown in Figure 4. 
Figure 4: Creep curves for OPC and aluminous concrete. Experimental data points from (Hummel, 1959). Numerical curves obtained by fitting $E_{p}, \eta_{p}$ and $\tau_{p}$ for the logarithmic creep model.

This result cannot be directly applied to Elleuch et al. experiments because of the difference in water/cement ratio, but it suggests that the creep viscosity $\eta_{p}$ is independent of the cement type, while the characteristic time $\tau_{p}$ is much higher. Therefore, we use the experiments of Wittmann (1970), who measured the creep of OPC pastes with a water/cement ratio of 0.4 (against 0.38 in Elleuch et al. experiments), to estimate $\eta_{p}$. We use the value of $\tau_{p}$ from the experiments of Hummel, even though it was measured on concrete rather than cement paste.

Finally, we use the same Poisson ratio for the creep and elastic deformations in absence of appropriate data concerning volumetric/deviatoric creep for aluminous cement paste.

Shrinkage. Elleuch et al. did not measure the deformation induced by the thermal treatment phase of their experimental procedure. However, they measured the loss of mechanical properties during that phase. The pulse velocity of the cement paste is reduced by approximately $10 \%$, which leads to an approximate loss of stiffness around 20\% after usage of (12-13). This gives the value of the thermal damage $d_{T}$ which appears in (3), while the value of the temperature thresholds $T_{1}$ and $T_{\max }$ were chosen respectively 
equal to 170 and $250^{\circ} \mathrm{C}$ based on experiments on mechanical experiments at high temperature on aluminous concrete from the work of Simonin (2000) in absence of more relevant data.

The concrete pulse velocity is also reduced during the thermal treatment. However, in the simulations, the loss of stiffness in the cement paste was not enough to reduce the concrete mechanical properties as much as in the experiments. This indicates that the thermal treatment phase produces micro-cracking in the material. Therefore, we adjusted the drying shrinkage so that damage initiates during that phase. We found a value of $k_{h}$ equal to $-1.2 \mathrm{~mm} \mathrm{~m}^{-1}$, which is close to the value used by Maruyama and Sugie (2014) to simulate the drying shrinkage of cement paste. After that value has been fixed, the damage properties of the cement paste were calibrated as described in the following section.

Elleuch et al. measured the irreversible drying shrinkage induced in the cement paste during the irradiation. This shrinkage is primarily caused by the sustained temperature in the irradiation rig rather than the neutron irradiation itself. However, there was a large scatter in the shrinkage measured, especially for the highest fluences. Therefore, we will consider two scenarios to provide lower and upper bounds for this additional shrinkage. It is neglected in the first approach: $k_{\Phi}=0$. In the second approach, it is described as a function of the neutron fluence, since it is a direct measure of the time spent under irradiation. An analysis of the experimental data provided a value of $k_{\Phi}$ equal to $-1.0 \mathrm{~mm} \mathrm{~m}^{-1} /\left(10^{+19}\right.$ n.cm $\left.{ }^{-2}\right)$ for fluences below $6 \times 10^{+19}$ n. $\mathrm{cm}^{-2}$. The shrinkage does not seem to increase beyond that point, therefore in the simulation the additional shrinkage during irradiation was capped 
to $-6.0 \mathrm{~mm} \mathrm{~m}^{-1}$.

Damage properties. The linear softening damage model used requires three independent parameters: the strength $f_{t}$, the ultimate strain at the end of the softening curve $\epsilon_{y, t}$ and the characteristic radius for the non-local averaging $r_{n l}$. While the strength is known from the experiments, both $\epsilon_{y, t}$ and $r_{n l}$ need to be defined using backward analysis of the numerical results against the experimental data. To do so, we used the thermal treatment phase, as the mechanical properties were measured before and after. During that phase, the concrete shows a reduction of stiffness and strength, which tends to indicate occurrence of micro-cracking in the material, but no macro-crack propagation.

We first calibrated $r_{n l}$ so that the apparent width of the damaged band (after calculation) would be the width imposed: for larger $r_{n l}$, the interactions between the different aggregates dominate and the apparent width of the damaged band becomes controlled by the size of the aggregates rather than $r_{n l}$ (Bažant and Pijaudier-Cabot, 1989). Bridging between aggregate becomes easier for high $r_{n l}$ and may lead to spurious macro-cracking. We chose a value which did not cause the sample to fail during the thermal treatment phase even for a purely brittle material $\left(\epsilon_{y, t}\right.$ equal to the strain at the peak $\left.E_{p} \times f_{t}\right)$.

Then we calibrate $\epsilon_{y, t}$ so that the loss of stiffness after thermal treatment would match the experimental results, accounting for the thermal damage $d_{T}$ in the cement paste. For high $\epsilon_{y, t}$, the material n.cm ${ }^{-2}$ is more ductile, which stabilizes the damage propagation. For low $\epsilon_{y, t}$, the material becomes more brittle, which may cause the propagation of a macro-crack through the 
sample. We found $\epsilon_{y, t}=0.5985 \mathrm{~mm} \mathrm{~m}^{-1}$, value at which point damage is initiated around the boundaries of the sample, but no macro-crack occurs.

Aggregate anisotropy. Elleuch et al. reported the coefficient of thermal expansion (CTE) and strength of aggregate for two different directions, showing thus the anisotropy of the material with respect to its foliation. In absence of relevant information about the aggregate microstructure, this effect is ignored in the simulations, and the average values of two directions were chosen when possible.

Table 2: Constitutive parameters used in the simulations. Unless noted otherwise, experimental data are from (Elleuch et al., 1972). (1) Experimental data. (2) Calculated from the experimental pulse velocity and density, Eq. (12-14). (3) Typical value for concrete. (4) Based on mechanical experiments for aluminous concrete by Simonin (2000). (5) Calibrated with numerical simulations of the thermal pre-treatment. (6) Based on creep experiments for OPC by Wittmann (1970). (7) Based on creep experiments for aluminous cement concrete by Hummel (1959). (8) Typical value for concrete recommended by Bažant and Baweja (2000). (9) Arbitrary parameter. (10) Experimental data, average of two directions. (11) Calibrated by Le Pape et al. (2015) on the experimental data.

\begin{tabular}{l|ll}
\hline Cement paste & & \\
$\rho_{p}\left[\mathrm{~kg} \mathrm{~m}^{-3}\right]$ & 2350 & $(1)$ \\
$E_{p}[\mathrm{GPa}]$ & 35.5 & $(2)$ \\
$\nu_{p}[-]$ & 0.2 & $(3)$ \\
$\alpha_{p}\left[\mu \mathrm{m} \mathrm{m}^{-1}{ }^{\circ} \mathrm{C}^{-1}\right]$ & 9 & $(1)$ \\
$T_{1}\left[{ }^{\circ} \mathrm{C}\right]$ & 170 & $(4)$ \\
$T_{\max }\left[{ }^{\circ} \mathrm{C}\right]$ & 250
\end{tabular}




\begin{tabular}{|c|c|c|}
\hline$d_{T}[-]$ & 0.2 & (1) \\
\hline$f_{c, p}[\mathrm{MPa}]$ & 120 & (1) \\
\hline$\epsilon_{y, c}\left[\mathrm{~mm} \mathrm{~m}^{-1}\right]$ & 5.25 & (5) \\
\hline$f_{t, p}[\mathrm{MPa}]$ & 17 & (1) \\
\hline$\epsilon_{y, t, p}\left[\mathrm{~mm} \mathrm{~m}^{-1}\right]$ & 0.5985 & (5) \\
\hline$r_{n l}[\mathrm{~mm}]$ & 0.18 & $(5)$ \\
\hline$k_{h}\left[\mathrm{~mm} \mathrm{~m}^{-1}\right]$ & -1.2 & (5) \\
\hline$h_{0}[-]$ & 0.6 & (1) \\
\hline$k_{\Phi}\left[\mathrm{mm} / \mathrm{m} /\left(10^{+19} \mathrm{n} \mathrm{cm}^{-2}\right)\right]$ & -1 & $(1)$ \\
\hline$\eta_{p}[\mathrm{GPad}]$ & 40 & (6) \\
\hline$\tau_{p}[\mathrm{~d}]$ & 12 & $(7)$ \\
\hline$T_{a c t}[\mathrm{~K}]$ & 5000 & $(8)$ \\
\hline$h_{c}[-]$ & 0.2 & (6) \\
\hline$\Delta d[-]$ & 0.1 & (9) \\
\hline Aggregate & & \\
\hline$\rho_{a}\left[\mathrm{~kg} \mathrm{~m}^{-3}\right]$ & 2800 & (1) \\
\hline$E_{a}[\mathrm{GPa}]$ & 97.3 & (2) \\
\hline$\nu_{a}[-]$ & 0.2 & (3) \\
\hline$\alpha_{a}\left[\mu \mathrm{m} \mathrm{m}^{-1}{ }^{\circ} \mathrm{C}^{-1}\right]$ & 7.5 & (10) \\
\hline$\epsilon_{\max }\left[\mathrm{mm} \mathrm{m}^{-1}\right]$ & 97.2 & (11) \\
\hline$\kappa\left[10^{-19} \mathrm{cmn}\right]$ & 0.0099 & (11) \\
\hline$\delta[-]$ & 84.268 & (11) \\
\hline
\end{tabular}




\section{Results of the Numerical Simulations}

Figure 5 presents the evolutions of the average deformation in the concrete and damage in the paste over time for a prolonged irradiation test in capsule G5, i.e., reaching fast-neutron fluence of about $10^{+20} \mathrm{n} . \mathrm{cm}^{-2}(E>1.0 \mathrm{MeV})$. This specific simulation, obtained with the assumptions that no additional shrinkage occurs during irradiation, is qualitatively representative of all the conducted simulations. Hence, the subsequent analysis can be generalized to all capsules. Damage in the paste is initiated at the end of the prethermal treatment phase, and appears to create bridges between the surface and the closest aggregate. Damage amplitude remains very moderate at that stage. Damage increases sharply immediately after the start of the irradiation test, grows rapidly during the first 50 days (i.e., to a corresponding

fluence of about $3.0 \times 10^{+19}$ n.cm ${ }^{-2}$ ), and tends to level off at a damage level of about 0.4-0.5 beyond 50 days. Damaged element bridges between the largest aggregates form rapidly (at $\approx 0.3 \times 10^{+20} \mathrm{n} . \mathrm{cm}^{-2}$ ) in the cement paste. Later, a damage layer appears homogeneously distributed around the aggregates. Simultaneously, similar damage patterns (bridges) develop around the smaller aggregates. At a later stage, damage continues spreading between the previously damaged zones.

Figure 6 shows the comparison of the post-irradiation expansions obtained experimentally by Elleuch et al. (o) with the mean value of $\epsilon_{x x}$ and $\epsilon_{y y}$ from the numerical simulations $(\square)$. The post-irradiation linear expansion corresponds to the variation of dimensional change of the specimens before and 
Figure 5: Average strain in concrete (solid line) and damage evolution (dashed line) for capsule G5 $\left(\mathrm{C}: 223{ }^{\circ} \mathrm{C}, 10.12 \times 10^{+19}\right.$ n.cm ${ }^{-2}$ at $\left.E>1.0 \mathrm{MeV}\right)$. The microstructures show the relative stiffness of the elements: aggregates appear in blue, cement paste in gray scale depending on the amount of damage (black corresponds to $d=1$ ). (a) pre-irradiation thermal treatment, (b) irradiation test, and (c) post-irradiation cool-off.

after irradiation. Experimentally, the post-irradiation expansion is measured after a cool-off period needed to decrease the activity level of the samples to a tolerable level. In Figure 6, this situation corresponds to the ( $\square$ ) symbols. The general trend of the computed post-irradiation expansions with increasing fluence is well correlated with the experimental measurements, although the amplitude is underestimated by nearly $1 \mathrm{~mm} \mathrm{~m}^{-1}$. When the experimental results (o) are compared to the expansion variation simulated immediately at the end of the irradiation test $(\boldsymbol{\square})$, the correlation in terms of amplitude is excellent. Acknowledging that the behavior of the paste is modeled by a damage model, no irreversible deformations during the unloading cool-off phase are accounted for, although important damage levels $(\approx 0.4)$ are obtained. Hence, the post-irradiation expansion calculated at the start of the cool-off period, provides a better estimation, if most of the deformation of the paste, i.e. cracking, is irreversible. This result corroborates earlier interpretations based on micromechanics theory (Le Pape et al., 2015): expansion of the aggregate caused by temperature increase and RIVE results in important paste damage and irreversible expansion of concrete. In Figure 6, the error bars correspond to the amplitude of variation between $\epsilon_{x x}$ and $\epsilon_{y y}$ 
(numerical results). At low fluences, the error is minimal indicating a nearly isotropic behavior of the specimen. The scatter increases at higher fluence. This apparent loss of isotropy can be explained by the cumulated effect of rather small size of the sample $(2.5 \mathrm{~cm}$ for a maximum aggregate size of 1.2 $\mathrm{cm})$ and of severe damage creation.

Figure 6: Post-irradiation (PI) expansions: (o): experimental data; (ם): PI-expansion before cool-off period; $(\square)$ : PI-expansion after cool-off period. The encapsulated numbers correspond to the capsule number (e.g., 3 for capsule G3). Error bars: amplitude of variation between $\epsilon_{x x}$ and $\epsilon_{y y}$. The gray-shade background corresponds to the $90 \%$ confidence interval on the experimental data - fit assuming (Zubov and Ivanov, 1966) equation, i.e., Eq. (11).

The results presented in Figure 6 do not account for additional shrinkage during irradiation, i.e., $k_{\Phi}=0$ in Eq. (9). In absence of loss of mass measurements, the actual shrinkage during irradiation is difficult to assess. In general, there is no correlation between the shrinkage of pure paste samples and the neutron fluence (Field et al., 2015). Hence, shrinkage is modeled by a bilinear model providing an upper-bound, in absolute value, of the post-irradiation shrinkage data provided in (Elleuch et al., 1972, Fig. 8). The results corresponding to this assumption are presented in Figure 7, ( $\square$ ) marks. Maximizing shrinkage deformation leads to an underestimation of the experimental data in the range of $4-7 \times 10^{+19}$ n.cm ${ }^{-2}$ ). For a given fluence, a couple of ( $\mathbf{\square}$ ) provides, in a certain sense, a lower and upper estimation of the post-irradiation expansion given the variability of additional shrinkage 
during the irradiation experiments.

Figure 7: Post-irradiation (PI) expansions: (o): experimental data; (ロ): PI-expansion maximizing the shrinkage during irradiation; $(\mathbf{\square})$ : PI-expansion minimizing the shrinkage during irradiation. The encapsulated numbers correspond to the capsule number (e.g., 3 for capsule G3). Error bars: amplitude of variation between $\epsilon_{x x}$ and $\epsilon_{y y}$. The gray-shade background corresponds to the $90 \%$ confidence interval on the experimental data - fit assuming (Zubov and Ivanov, 1966) equation, i.e., Eq. (11).

Figure 8 shows the evolution of deformation and damage through time for the capsule $\mathrm{G} 5\left(\mathrm{C}: 223^{\circ} \mathrm{C}, 10.12 \times 10^{+19}\right.$ n.cm ${ }^{-2}$ at $\left.E>1.0 \mathrm{MeV}\right)$ with and without the additional shrinkage. The differential strain between the shrinkage in the paste and the RIVE in the aggregate causes the material to fail earlier than without shrinkage, while reducing the macroscopic expansion.

Figure 8: Average strain in concrete and damage in the cement paste with additional shrinkage during irradiation (bold lines) and without (thin lines). The microstructures correspond to the simulation with the additional shrinkage.

Numerically-derived damage (average value in the cement paste) is compared to the theoretically-derived damage, i.e., crack density estimated, in the sense of Budiansky and O'Connell (1976) assuming a tridimensional self-consistent micromechanical model for irradiated concrete developed by Le Pape et al. (2015) - Fig. 9. Note that, a crack density of 9/16 corresponds 
theoretically to a complete loss of elastic stiffness. The comparison between the two approaches is to be made cautiously. The trends of the levels of damage calculated by both methods are comparable. The numerically-derived damage assuming the absence of shrinkage during irradiation is, as expected, lower (by about 0.1) than the damage derived accounting for shrinkage during irradiation. The damage rate appears higher for fluence below $3.0 \times 10^{+19}$ n.cm ${ }^{-2}$. The amplitude of damage confirms the previous theoretical results showing the large extent of damage produced during the radiation experiment.

Figure 9: Post-irradiation (PI) damage in the paste: (०): micromechanical interpretation from experimental data (Le Pape et al., 2015); (匹): damage obtained when maximizing the shrinkage during irradiation; (ם): damage obtained when minimizing the shrinkage during irradiation. The encapsulated numbers correspond to the capsule number (e.g., 3 for capsule G3).

\section{Discussions}

A certain number of parameters were not well characterized in Elleuch et al. experiments and thus needed to be assumed. Some of the uncertainties induced by these assumptions are evaluated and discussed in this section.

\subsection{Microstructure Effects}

We used the same microstructure and mesh represented in Figure 1 in the previous set of simulations. In this case, the sample is not a representative el- 
Figure 10: Variability in expansion and damage with different random microstructures. Capsule G3 (temperature $202^{\circ} \mathrm{C}$, fluence $3.32 \times 10^{+19}$ n.cm ${ }^{-2}$ ).

ementary volume as the diameter of the largest aggregate $(12 \mathrm{~mm})$ is around one-half the width of the sample $(25 \mathrm{~mm})$. The position of the central largest inclusion may have a significant influence on the simulated results, as cracking initiates between that aggregate and its largest neighbours. To assess the scatter caused by the heterogeneities in the microstructure, we repeat the set of simulations from the G3 capsule (temperature $202^{\circ} \mathrm{C}$, fluence $3.32 \times 10^{+19}$ n.cm ${ }^{-2}$ ). Five different random microstructures are generated with the same particle size distribution. The area, i.e. volume fraction, covered by aggregates elements after meshing is fairly consistent from one microstructure to another (less than $0.1 \%$ relative variation).

Figure 10 represents the expansion and damage for each microstructure compared to the reference value found in the previous section. Interestingly, the expansion seems in general higher in these microstructures than in the reference. This can be explained by the fact that in the reference, the largest aggregate particle is located around the center of the sample, so its expansion is homogeneously restrained. In the other microstructures, that particle is generally closer to the boundaries of the sample, which allows it to deform more freely in one or two directions.

These simulations indicate that the samples used in the experiments may not be representative of the material, and that this lack of representativity 
might account for 5 to $10 \%$ of the experimental scatter for this level of fluence. However, this effect might also be exacerbated by the two-dimensional nature of the simulation. Accounting for the third dimension would provide an additional restraint which may thus reduce the numerical scatter.

\subsection{Role of radiation-induced damage in the aggregates}

In their experiments, Elleuch et al. measured a loss of pulse velocity of the aggregates after exposure to neutron irradiation, which translates into a loss of elastic stiffness. This effect is not accounted for in the previous simulations, under the assumption that the damage in the microstructure is driven by the very high value of the RIVE. In order to test this hypothesis, we repeat the simulation of the G5 capsule (temperature $223^{\circ} \mathrm{C}$, fluence $10.12 \times 10^{+19}$ n.cm ${ }^{-2}$ ) accounting for the reduction of the aggregates Young's modulus of the aggregate when the fluence increases. We use the bi-linear fit of the pulse velocity data from Le Pape et al. (2015), followed by (12)-(14) to obtain the Young's modulus at a given fluence. The Young's modulus of the aggregate then varies from its initial value of $97.3 \mathrm{GPa}$ to $60.8 \mathrm{GPa}$ at $\Phi=1 \times 10^{19} \mathrm{n} / \mathrm{cm}^{2}$ and $43.0 \mathrm{GPa}$ at $\Phi=10 \times 10^{19} \mathrm{n} / \mathrm{cm}^{2}$. This significant loss of stiffness might reduce the pressure exerted by the RIVE, and therefore the propagation of damage in the microstructure.

The expansion and damage as a function of the time for the selected capsule are shown in Figure 11 (bold lines), and compared to the results obtained with the constant stiffness (thin lines). The reduction of the aggregate Young's modulus does not significantly affect the results. This is due to the fact that most of the damage occurs early in this accelerated irradiation process, and is dominated by the pressure the RIVE exerts on the cement paste 
Figure 11: Average strain in concrete and damage in the cement paste when the stiffness of the aggregate is reduced with the neutron fluence (bold lines) or is constant (thin lines). The microstructures correspond to the simulated damage pattern with the reduction of the aggregate stiffness under irradiation.

(proportional to $E_{a} \times \epsilon_{\Phi}$ ). This pressure is much higher than the cement's strength, and the stiffness of the aggregate is not reduced enough at that stage to alter significantly this initial damage. At later stages, the damage in the microstructure is so widespread that the cement paste does not restraint the aggregate RIVE, and therefore the loss of stiffness in the aggregate does not influence this stage as well.

This conclusion stems mainly from the brittleness of the cement, and the homogeneity of the aggregate. It may not hold for different materials or conditions.

\subsection{Role of creep}

The aluminous cement paste used by Elleuch et al. creeps at a slower rate than an ordinary cement paste, according to the results of Hummel (1959). Notably, short-term creep seems very low, which would indicate that the material exhibits slow stress relaxation as well. In these conditions, and considering the very high damage induced by the RIVE, the question of the relevance of creep and stress relaxation is raised.

Therefore, we repeat the simulation G5 (temperature $223^{\circ} \mathrm{C}$, fluence $10.12 \times 10^{+19}$

n. $\mathrm{cm}^{-2}$ ) without creep in the cement paste. All other effects (strain soft- 
ening, dependence on temperature and humidity, shrinkage) are conserved. Figure 12 shows the difference in expansion and in damage as a function of time with creep (thin lines) and without (bold lines).

Figure 12: Average strain in concrete and damage in the cement paste with creep (thin lines) and without (bold lines). The microstructures correspond to the simulation without creep.

Results are almost identical to the simulations with creep, which indicate that under this condition, creep has little effect on the irradiation-induced damage and expansion. Two phenomena can explain this behavior: 1) The aluminous cement paste creeps at a much slower rate than OPC. Notably, stress relaxation does not occur until approximately 10 days after deformation. This result might not be applicable for a material with a higher creep rate such as OPC ; 2) The reduction of creep at low relative humidity dominates the acceleration caused by the high temperature. If this is the case, then this result might be applicable to OPC concrete and therefore to the analysis of actual structures. Given the low sensitivity of the model to creep for this specific material, the uncertainty on associated parameters (activation energy, drying creep, etc) is not assessed in the current work.

This absence of effect of creep on the simulated expansion and damage is also tied to the post-peak behavior of the cement paste and the aggregate morphology. Describing aggregate as a polyphasic material with mineral phases expanding at different rates could change dramatically the damage 
propagation in the material, which in turn would make the sample more susceptible to creep and stress relaxation. If the cement paste is more ductile for slower loading rates, as suggested by Bažant and Gettu (1992), then the role of creep might be more visible, as the influence of the stress relaxation on the damage onset and propagation in the microstructure would be higher. This effect is highlighted in the next section. Finally, the importance of creep might be magnified if the material were restrained or loaded at it is the case in real structures. So, even if in this set of simulations, creep does not seem to have any significant influence on the apparent expansion and damage, this conclusion cannot be generalized to operating conditions of LWRs.

\subsection{Role of strain softening}

In the present model, we assumed that cement paste was a quasi-brittle material with a linear softening behavior, which is consistent with quasistatic failure experiments on concrete. However, Bažant and Gettu (1992) found that for slow loading rates, the apparent failure behavior of concrete shifted from brittle failure at fast strain rates, to a more ductile behavior at slow strain rate. The transition reported in their experiments occurs for strain rates between 0.08 and $0.8 \mathrm{~mm} \mathrm{~m}^{-1} \mathrm{~d}$. In the simulations, the strain rate recorded is around $0.03 \mathrm{~mm} \mathrm{~m}^{-1} \mathrm{~d}$, which would indicate the material is in the ductile regime. This effect is related to the creep in the cement paste, so it would be not as prominent with the aluminous cement that Elleuch et al. used. This remains purely speculative though, as there are not enough data concerning the creep or failure of aluminous cement on one hand, and the concrete in Bažant and Gettu were tested at different ages on the other hand, making the actual comparison difficult. 
The long-term material behavior, however, might not be represented with a softening branch, but as a pseudo-plastic material, in which damage increases at constant stress. We repeated the simulation G5 (temperature $223^{\circ} \mathrm{C}$, fluence $10.12 \times 10^{+19}$ n.cm ${ }^{-2}$ ) with a failure criterion in stress: Eq. (10) used to determine when damage increases is replaced with the following relation:

$$
\|\bar{\sigma}\|-f_{t}=0
$$

An element has therefore no strain limit, and is able to reach very large deformations as long as its stress (accounting for current damage and stress relaxation) remains under the material strength. All other parameters (occurrence of creep, dependence on temperature and humidity, shrinkage, etc) are kept unchanged. Figure 13 shows the difference in expansion and in damage as a function of the total fluence.

Figure 13: Average strain in concrete and damage in the cement paste with a ductile (bold lines) and brittle (thin lines) post-peak behavior of the cement paste. The microstructures correspond to the simulation with the ductile behavior.

At the beginning of irradiation, the expansion follows the expansion found with the linear softening behavior, but the onset of damage is delayed. This is an effect of the relaxation in the cement paste, which reduces the stresses in the material, and therefore delays the instant at which the material reaches its strength. The creep properties used in the present model are deemed 
representative of aluminous cement paste, which creeps at a slower rate than OPC. It is likely that with OPC, the higher stress relaxation would further delay the onset of damage.

At the end of the irradiation, the damage and the expansion are higher than what is found with the linear softening behavior. Furthermore, the damage is more homogeneously spread over the microstructure, when the linear softening behavior causes much more localized "cracks". This is an effect of the fracture energy available to the material during the damage process. With the criterion in stress, an element is still able to bear loads for very high strains (higher than the elastic limit of the material), and thus transmit its deformation to the neighbour elements, leading them to progressive failure. With the linear softening behavior, a fully damaged element cannot bear loads for strain higher than its ultimate tensile strain $\epsilon_{y, t}$, and therefore cannot restrain the deformation of the neighbour elements, limiting the spread of damage to the non-local band of elements. This effect is consistent with the observations of Bažant and Gettu (1992), who noticed that for fast strain rates (linear softening behavior) the damage pattern was formed by a network of microcracks, while for slow strain rates (stress criterion) a larger macro-crack appears.

The pseudo-plastic material used in this section is an upper bound of the material post-peak behavior, and thus provides an upper bound for the expansion and damage, while the linear softening formulation represents a lower bound.

These simulations highlight the importance of the characterization of the material failure behavior as a function of the loading rate. The proposed 
model is strongly sensitive to the post-peak behavior of the cement paste. From a practical perspective, failure experiments at very slow loading rates of concretes representative of the CBS, complemented with creep and shrinkage experiments for the same concrete and the same age, would provide calibration data for the material parameters required by the model. In absence of these data, the model is still able to provide upper and lower bounds of the expansion and damage by assuming a brittle or pseudo-plastic behavior.

\subsection{Summary}

Five different hypotheses were evaluated with the model: 1) Reference simulation with creep, brittle failure and no additional shrinkage in the cement paste, and with constant aggregate stiffness. 2) Simulation with additional shrinkage during irradiation. 3) Simulation with loss of aggregate stiffness with the fluence. 4) Simulation without creep in the cement paste. 5) Simulation with a ductile failure in the cement paste to represent long-term operational conditions.

Figure 14: Average strain in concrete as a function of the average damage in the cement paste for the reference simulation, simulation with ductile behavior in the cement paste, and simulation with additional shrinkage during irradiation. $\mathrm{b} \rightarrow \mathrm{d}$ : brittle-ductile transition; $\rightarrow \mathrm{s}$ : accounting for the effect of additional shrinkage during irradiation

In these simulations, only the consideration of additional shrinkage during

the irradiation phase and the ductile failure in the cement paste seemed to have an impact on the development of the degradation. Figure 14 shows 
Figure 15: Damage patterns for the capsule G5 (temperature $223^{\circ} \mathrm{C}$, total fluence $10.12 \times 10^{+19}$ n. $\mathrm{cm}^{-2}$ ) with three different model hypotheses, at three different instant: before irradiation (after the thermal pre-treatment phase), during the start of the irradiation $\left(\Phi=1.09 \times 10^{+19} \mathrm{n} . \mathrm{cm}^{-2}\right)$, and at the end of irradiation $\left(\Phi=10.12 \times 10^{+19} \mathrm{n} . \mathrm{cm}^{-2}\right)$. Aggregate is represented in blue, cement paste in level of gray depending on the value of the damage in the element (white for $d=0$, black for $d=1$ ).

the evolution of the concrete expansion as a function of the average damage in the cement paste, while Figure 15 shows the damaged microstructure at three different stages of radiation. With the brittle post-peak behavior of the cement paste, the damage is localized around and in-between the aggregate particles. With the ductile post-peak behavior, the damage is more spread through the microstructure, which leads to a higher overall damage at the same degree of expansion. However, the onset of damage is slightly delayed, and it can be expected that this delay would be higher for a material with a faster stress relaxation. With additional shrinkage in the cement paste during irradiation, the onset of damage occurs earlier because of the differential strain between the shrinkage and the RIVE. Furthermore, there is more damage in the material for the same apparent expansion.

This highlights the importance of the different components of the model on the simulated results. The curves from Figure 14 can be used to develop a macroscopic model for irradiated concrete. However, such upscaling must be done with parameters representative of the materials used in CBS. Notably, these results might differ with a cement paste exhibiting a faster creep 
rate. In the present model, we considered an aluminous cement paste with a very slow creep compared to OPC, which causes the relaxation through micro-cracking to dominate compared to the visco-elastic stress relaxation. Furthermore, we assumed the aggregate was homogeneous in absence of relevant data, but it can be suspected that the damage propagation would greatly differ with polyphasic aggregate, as it is the case in meso-scale simulation of ASR.

\section{Conclusions}

We simulated the expansion and damage propagation of concrete subjected to irradiation based on the experimental procedure described by Elleuch et al. (1972). The parameters of the model were carefully calibrated using regression analysis of experimental data when available. Missing parameters were assumed based on theoretical arguments or existing data previously accepted by the research community. Backward numerical analysis was used for parameters which are difficult to access experimentally such as the radius of the non-local damage model or the ultimate strain at complete failure.

The RIVE of serpentine aggregate causes the development and propagation of damage around the aggregate, and across the hardened cement paste, developing bridging cracks between the aggregates. The post-irradiation expansions derived from the simulation are well correlated with the experimental data, and the obtained damage levels are fully consistant with previous estimations based on a micromechanical interpretation of the experimental post-irradiation elastic properties (Le Pape et al., 2015).

The proposed modeling opens new perspectives for the interpretation of 
test reactor experiments in regards to the actual operation of light water reactors. The transposition to the environmental conditions and time scales of these structures is not immediate and requires careful consideration, as well as a fine characterization of the material properties.

\section{Acknowledgements}

This research is sponsored by the U.S. Department of Energy (DOE) Light Water Reactor Sustainability Program. This manuscript has been authored by UT-Battelle, LLC under Contract No. DE-AC05-00OR22725 with the U.S. Department of Energy. The United States Government retains and the publisher, by accepting the article for publication, acknowledges that the United States Government retains a non-exclusive, paid-up, irrevocable, world-wide license to publish or reproduce the published form of this manuscript, or allow others to do so, for United States Government purposes. The Department of Energy will provide public access to these results

of federally sponsored research in accordance with the DOE Public Access Plan (http://energy.gov/downloads/doe-public-access-plan).

The Czech co-authors were financially supported by project SGS15/035/ OHK1/1T/11 of the Czech Technical University in Prague, which is gratefully acknowledged. This work was also sponsored by the IAEA, under the TC RER035 project.

\section{References}

Baggio, P., Majorana, C., Schrefler, B., 1995. Thermo-hygro-mechanical analysis of concrete. International Journal for Numerical Methods in Fluids 
$20,573-595$.

Baroghel-Bouny, V., Mainguy, M., Lassabatere, T., Coussy, O., 1999. Characterization and identification of equilibrium and transfer moisture properties for ordinary and high-performance cementitious materials. Cement and concrete research 29, 1225-1238.

Bary, B., Ranc, G., Durand, S., Carpentier, O., 2008. A coupled thermohydro-mechanical-damage model for concrete subjected to moderate temperatures. International Journal of Heat and Mass Transfer 51, 2847-2862.

Bažant, Z., Baweja, S., 2000. Creep and shrinkage prediction model for analysis and design of concrete structures: Model B3. ACI Special Publications $194,1-84$.

Bažant, Z., Gettu, R., 1992. Rate effects and load relaxation in static fracture of concrete. ACI Materials Journal 89.

Bažant, Z., Pijaudier-Cabot, G., 1989. Measurement of characteristic length of nonlocal continuum. Journal of Engineering Mechanics 115, 755-767.

Bažant, Z., Yu, Q., Li, G., 2012. Excessive long-time deflections of prestressed box girders. i: Record-span bridge in Palau and other paradigms. Journal of Structural Engineering 138, 676-686.

Benboudjema, F., Meftah, F., Torrenti, J., 2005. Interaction between drying, shrinkage, creep and cracking phenomena in concrete. Engineering structures 27, 239-250. 
Bengougam, A., 2002. Déformations différées et effet d'échelle des bétons de barrage. Ph.D. thesis. École Polytechnique Fédérale de Lausanne.

Bibler, N., 1978. Radiolytic gas production from concrete containing Savannah River plant waste. Technical Report DP-1464. Savannah River Laboratory. Aiken, SC 29801.

Bonnet, J., Boissier, M., Gherbi, A.A., 1994. The amorphization process of neutron-irradiated crystalline quartz studied by Brillouin scattering. Journal of Non-Crystalline Solids 167, 199-204.

Bouniol, P., Aspart, A., 1998. Disappearance of oxygen in concrete under irradiation: the role of peroxides in radiolysis. Cement and Concrete Research 28, $1669-1681$.

Bouniol, P., Muzeau, B., Dauvois, V., 2013. Experimental evidence of the influence of iron on pore water radiolysis in cement-based materials. Journal of Nuclear Materials 437, 208-216.

Brandt, A., Jóźwiak-Niedźwiedzka, D., 2013. The influence of ionizing radiation on microstructure and properties of concrete shields a review. cement wapno beton 4, 216-237.

Budiansky, B., O'Connell, R., 1976. Elastic moduli of a cracked solid. International Journal of Solids and Structures 12, 81-97.

van Buskirk, R., Enniss, D., Schatz, J., 1985. Measurement of Rock Properties at Elevated Temperatures and Pressures. American Society for Testing and Materials. chapter Measurement of thermal conductivity and thermal 
expansion at elevated temperatures and pressures. ASTM STP 869, pp. $108-127$.

Bylov, V., Denisov, A., Dubrovskii, V., Korenevskii, V., Krivokoneva, G., Muzalevskii, L., 1981. Effect of irradiation temperature on the radiation expansion of quartz. Atomnaya Energiya 51, 593-595.

Crawford, H.J., Wittels, M., 1956. A review of investigations of radiation effects in covalent and ionic crystals, in: Proceedings of International Conference on Peaceful Uses of Atomic Energy, United Nations, New York.. pp. 654-665.

Crawford, H.J., Wittels, M., 1958. Radiation stability of nonmetals and ceramics, in: Proceedings of the Second U.N. International Conference on the Peaceful Uses of Atomic Energy, p. 300.

Douillard, L., Duraud, J., 1996. Amorphization of alpha-quartz under irradiation. Journal de Physique III 6, 1677-1687.

Du, C.B., Sun, L.G., 2007. Numerical simulation of aggregate shapes of two-dimensional concrete and its application 1. Journal of Aerospace Engineering 20, 172-178.

Dunant, C., Bentz, E., 2015. Algorithmically imposed thermodynamic compliance for material models in mechanical simulations using the aim method. International Journal for Numerical Methods in Engineering .

Dunant, C., Scrivener, K., 2010. Micro-mechanical modelling of alkali-silicareaction-induced degradation using the amie framework. Cement and Concrete Research 40, 517-525. 
Dunant, C., Scrivener, K., 2012. Effects of uniaxial stress on alkali-silica reaction induced expansion of concrete. Cement and concrete research 42, $567-576$.

Dupray, F., Malecot, Y., Daudeville, L., Buzaud, E., 2009. A mesoscopic model for the behaviour of concrete under high confinement. International journal for numerical and analytical methods in geomechanics 33, 14071423.

Eissa, E., Kazi, A., 1988. Relation between static and dynamic young's moduli of rocks. International Journal of Rock Mechanics and Mining Sciences \& Geomechanics Abstracts 25, 479-482.

Elleuch, L., Dubois, F., Rappeneau, J., 1972. Effects of neutron radiation on special concretes and their components. Special Publication of The American Concrete Institute 43, 1071-1108.

Fei, Y., 1995. Thermal Expansion, in Mineral Physics \& Crystallography: A Handbook of Physical Constants. Wiley, American Geophysical Union, Washington, D.C.

Field, K., Remec, I., Le Pape, Y., 2015. Radiation Effects on Concrete for Nuclear Power Plants, Part I: Quantification of Radiation Exposure and Radiation Effects. Nuclear Engineering and Design 282, 126-143.

Fillmore, D., 2004. Literature Review of the Effects of Radiation and Temperature on the Aging of Concrete. Technical Report INEEL/EXT-04-02319. Idaho National Engineering and Environmental Laboratory. 
Frondel, C., 1945. Effect of radiation on the elasticity of quartz" ( vol. 30, 1945). American Mineralogist 30, 432-446.

Fujiwara, K., Ito, M., Sasanuma, M., Tanaka, H., Hirotani, K., Onizawa, K., Suzuki, M., Amezawa, H., 2009. Experimental study of the effect of radiation exposure to concrete, in: Proceedings of the 20th International Conference on Structural Mechanics in Reactor Technology, Espoo, Finland.

Fuller, W., Thompson, S., 1907. The laws of proportioning concrete. Journal of Transportation Division, American Society of Civil Engineers 59, 67143.

Giorla, A., 2013. Modelling of alkali-silica reaction under multi-axial load. Ph.D. thesis. École Polytechnique Fédérale de Lausanne, n5982.

Giorla, A., Scrivener, K., Dunant, C., 2014. Finite elements in space and time for the analysis of generalised visco-elastic materials. International Journal for Numerical Methods in Engineering 97, 454-472.

Giorla, A., Scrivener, K., Dunant, C., 2015. Influence of visco-elasticity on the stress development induced by alkali-silica reaction. Cement and Concrete Research 70, 1-8.

Grasley, Z., Lange, D., 2007. Thermal dilation and internal relative humidity of hardened cement paste. Materials and Structures 40, 311-317.

Graves, H., Le Pape, Y., Naus, D., Rashid, J., Saouma, V., Sheikh, A., Wall, J., 2014. Expanded Material Degradation Assessment (EMDA), Volume 
4: Aging of Concrete. Technical Report NUREG/CR-7153, ORNL/TM2011/545. U.S. Nuclear Regulatory Commission.

Hauser, O., Schenk, M., 1964. Veränderungen der Kristallstruktur einiger Oxyde, Karbonate und Titanate durch Neutronenbestrahlung. Physica Status Solidi B 6, 83-88.

Hilaire, A., Benboudjema, F., Darquennes, A., Berthaud, Y., Nahas, G., 2014. Modeling basic creep in concrete at early-age under compressive and tensile loading. Nuclear Engineering and Design 269, 222-230.

Hilsdorf, H., Kropp, J., Koch, H., 1978. The effects of nuclear radiation on the mechanical properties of concrete. Special Publication of The American Concrete Institute 55, 223-254.

Hummel, A., 1959. Vom Einfluss der Zementart, des Wasserzementverhaltnisses und des Belastungalters auf das Kriechen des Betons. Zement-KalkGips 5, 181-187.

Jirásek, M., 2004. Non-local damage mechanics with application to concrete. Revue française de génie civil 8, 683-707.

Johnson, W., Parsons, W., 1944. Thermal expansion of concrete aggregate materials. Journal of Research of the National Bureau of Standards 32, $101-126$.

Kelly, B., Brocklehurst, J., Mottershead, D., McNearney, S., Davidson, I., 1969. The effects of reactor radiation on concrete, in: Proceedings of the Second Information Meeting on Pre Stress Concrete and Reactor Pressure Vessels and their Thermal Isolation, Brussels, pp. 237-265. 
Komonen, J., Penttala, V., 2003. Effects of high temperature on the pore structure and strength of plain and polypropylene fiber reinforced cement pastes. Fire technology 39, 23-34.

Kontani, O., Ichikawa, Y., Ishizawa, A., Takizawa, M., Sato, O., 2010. Irradiation effects on concrete structure, in: International Symposium on the Ageing Management and Maintenance of Nuclear Power Plants, pp. 173-182.

Kontani, O., Sawada, S., Maruyama, I., Takizawa, M., Sato, O., 2013. Evaluation of irradiation effects on concrete structure - gamma ray irradiation tests on cement paste, in: Proceedings of the ASME 2013 Power Conference POWER2013, Boston, MA, USA.

Lavergne, F., Sab, K., Sanahuja, J., Bornert, M., Toulemonde, C., 2015. Investigation of the effect of aggregates' morphology on concrete creep properties by numerical simulations. Cement and Concrete Research 71, $14-28$.

Le Pape, Y., Field, K., Remec, I., 2015. Radiation Effects in Concrete for Nuclear Power Plants - Part II: Perspective from Micromechanical Modeling. Nuclear Engineering and Design 282, 144-157.

Lowinska-Kluge, A., Piszora, P., 2008. Effect of gamma irradiation on cement composites observed with XRD and SEM methods in the range of radiation dose 0-1409 mgy. Acta Physica Polonica-Series A General Physics 114, 399.

Luthra, J., 1969. X-ray studies on pile-irradiated calcite. Indian Journal of Pure and Applied Physics 7, 444-. 
Mainguy, M., Coussy, O., Baroghel-Bouny, V., 2001. Role of air pressure in drying of weakly permeable materials. ASCE Journal of Engineering Mechanics 127, 582-592.

Maréchal, J.C., 1969. Le fluage du béton en fonction de la température. Matériaux et Construction 2, 111-115.

Maruyama, I., Kontani, O., Ishizawa, A., Takizawa, M., Sato, O., 2012. Development of system for evaluating concrete strength deterioration due to radiation and resultant heat, in: 3rd International Conference on NPP Life Management for Long Term Operations, Salt Lake City, USA.

Maruyama, I., Kontani, O., Sawada, S., Sato, O., Igarashi, G., Takizawa, M., 2013. Evaluation of irradiation effects on concrete structure - Background and preparation of neutron irradiation test, in: Proceedings of the ASME 2013 Power Conference POWER2013, Boston MA, USA.

Maruyama, I., Nishioka, Y., Igarashi, G., Matsui, K., 2014a. Microstructural and bulk property changes in hardened cement paste during the first drying process. Cement and Concrete Research 58, 20-34.

Maruyama, I., Sasano, H., Nishioka, Y., Igarashi, G., 2014b. Strength and Young's modulus change in concrete due to long-term drying and heating up to $90^{\circ} \mathrm{C}$. Cement and Concrete Research 66, 48-63.

Maruyama, I., Sugie, A., 2014. Numerical study on drying shrinkage of concrete affected by aggregate size. Journal of Advanced Concrete Technology 12, 279-288. 
McDowall, D., 1971. The effect of gamma irradiation on the creep properties of concrete, in: Proceedings of an Information Exchange Meeting on Results of Concrete Irradiation Programmes, Commission of the European Communities. pp. 55-69.

de Morais, M., Bary, B., Ranc, G., Dal Pont, S., Durand, S., 2009. Comparative analysis of coupled thermo-hydro-mechanical models for concrete exposed to moderate temperatures. Numerical Heat Transfer, Part A: Applications: An International Journal of Computation and Methodology 55, 654-682.

Naus, D., 2005. The Effect of Elevated Temperature on Concrete Materials and Structures - A Literature Review. Technical Report ORNL/TM2005/553. Oak Ridge National Laboratory. Oak Ridge, TN.

Naus, D., 2010. A Compilation of Elevated Temperature Concrete Material Property Data and Information for Use in Assessments of Nuclear Power Plant Reinforced Concrete Structures. US Nuclear Regulatory Commission, Office of Nuclear Regulatory Research.

Neville, A., 1960. Recovery of creep and observations on the mechanism of creep of concrete. Applied Scientific Research 9, 71-84.

Pickett, G., 1942. The effect of change in moisture content on the creep of concrete under sustained load. Journal of the American Concrete Institute $38,333-355$.

Pijaudier-Cabot, G., Bazant, Z.P., 1987. Nonlocal damage theory. Journal of Engineering Mechanics 113, 1512-1533. 
Pomaro, B., Salomoni, V., Gramegna, F., Prete, G., Majorana, C., 2011. Radiation damage evaluation on concrete within a facility for selective production of exotic species (SPES Project), Italy. Journal of Hazardous Materials 194, 169-177.

Primak, W., 1958. Fast-neutron-induced changes in quartz and vitreous silica. Physical Review 110, 1240-1254.

Rappeneau, J., Lagorio, M., Gilbert, J., Piron, P., 1966. Irradiation tests of concretes. Bulletin d'Information Scientifique et Technique 110, 31-48.

Remec, I., 2013. Radiation environment in concrete biological shields of nuclear power plants. Light Water Reactor Sustainability Program.

Remec, I., 2014. Status Report on Defining a Unified Parameter for Characterization of Radiation Intended for Evaluation of Radiation-Induced Degradation of Concrete. Technical Report. Oak Ridge National Laboratory.

Rosseel, T., Wall, J., Field, G., Le Pape, Y., Naus, D., Remec, I., Busby, J., Bruck, P., 2014. Radiation damage in reactor cavity concrete, in: Fontevraud 8 - Contribution of Materials Investigations and Operating Experience to LWRs' Safety, Performance and Reliability, Avignon, France.

Rots, J., Invernizzi, S., 2004. Regularized sequentially linear saw-tooth softening model. International Journal for Numerical and Analytical Methods in Geomechanics 28, 821-856.

Rusch, H., 1960. Researches toward a general flexural theory for structural concrete. ACI Journal Proceedings 57. 
Salomoni, V., Majorana, C., Pomaro, B., Xotta, G., Gramegna, F., 2014. Macroscale and mesoscale analysis of concrete as a multiphase material for biological shields against nuclear radiation. International Journal for Numerical and Analytical Methods in Geomechanics 38, 418-535.

Seeberger, J., Hilsdorf, H., 1982. Einfluss von Radioaktiver Strahlung auf die Festigkeit und Struktur von Beton. Technical Report NR2505. Institüt fur Massiubau und Baustofftechnologie, Arbeitlung Baustofftechnologie, Universität Karlsruhe, Germany.

Shahidi, M., Pichler, B., Hellmich, C., 2014. Viscous interfaces as source for material creep: A continuum micromechanics approach. European Journal of Mechanics-A/Solids 45, 41-58.

Simonin, F., 2000. Comportement thermomécanique de bétons réfractaires alumineux contenant du spinelle de magnésium. Ph.D. thesis. National Institute of Applied Sciences (INSA), Lyon, France.

Soo, P., Milian, L., 1989. Sulfate-Attack Resistance and Gamma-Irradiation Resistance of Some Portland Cement Based Mortars. Technical Report NUREG/CR-5279 BNL-NUREG52179 RW. Brookhaven National Laboratory. Upton NY 11973.

Sopko, V., Trtik, K., Vodák, F., 2004. Influence of gamma irradiation on concrete strength. Acta Polytechnica 44, 57-58.

Ulm, F.J., Le Maou, F., Boulay, C., 1999. Creep and shrinkage coupling: new review of some evidence. 
Vandamme, M., Ulm, F., 2009. Nanogranular origin of concrete creep. Proceedings of the National Academy of Sciences 106, 10552-10557.

Vodák, F., Trtik, K., Kapičková, O., Hošková, v., Demo, P., 2004. The effect of temperature on strength - porosity relationship for concrete. Construction and Building Materials 18, 529-534.

Vodák, F., Vydra, V., Trtik, K., Kapičková, O., 2011. Effect of gamma irradiation on properties of hardened cement paste. Materials and Structures 44, 101-107.

William, K., Xi, Y., Naus, D., 2013. A Review of the Effects of Radiation on Microstructure and Properties of Concretes Used in Nuclear Power Plants. Technical Report NUREG/CR-7171 ORNL/TM-2013/263. U.S. Nuclear Regulatory Commission. Washington, DC 20555-0001.

Wittels, M., 1957. Structural behavioor of neutron irradiated quartz. Philosophical Magazine 2, 1445-1461.

Wittmann, F., 1970. Einfluß des Feuchtigkeitsgehaltes auf das Kriechen des Zementsteines. Rheologica Acta 9, 282-287.

Wittmann, F., 1973. Interaction of hardened cement paste and water. Journal of the American ceramic society 56, 409-415.

Zinkle, S., 2012. Comprehensive Nuclear Materials. Elsevier, Amsterdam. volume 1. chapter Radiation-Induced Effects on Microstructure. pp. 6598. 
Zubov, V., Ivanov, A., 1966. Expansion of quartz caused by irradiation with fast neutrons. Soviet Physics Crystallography 11, 372-374. 


\section{Figure}

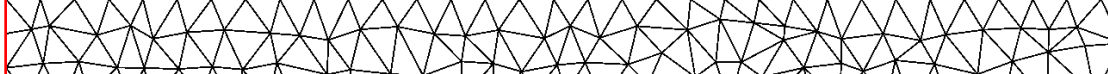

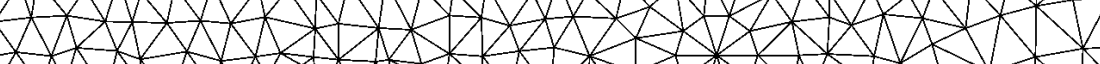

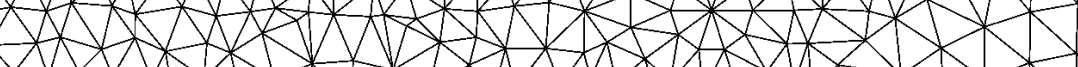

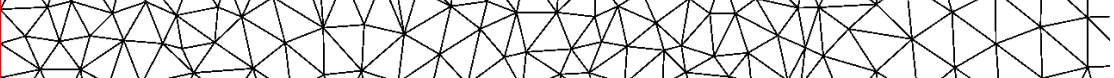

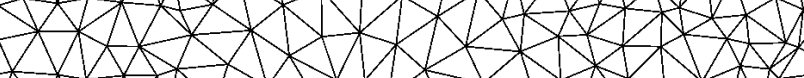

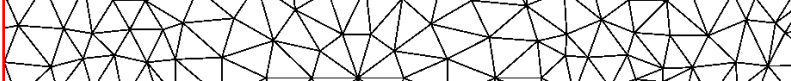

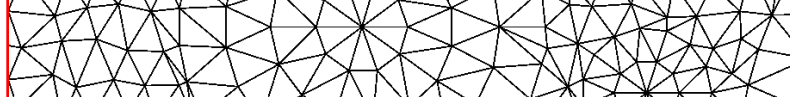
$4 \times 1 \times 1+2$

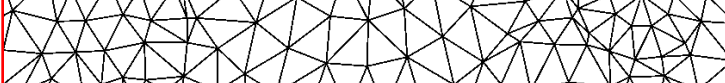

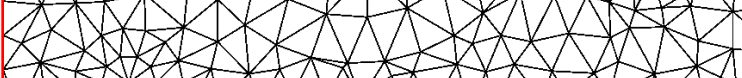

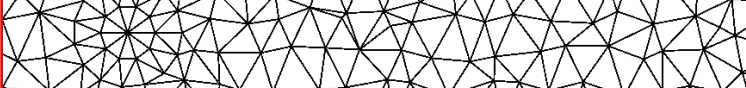

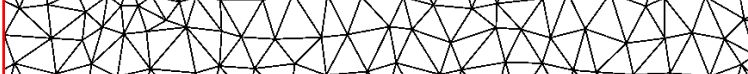

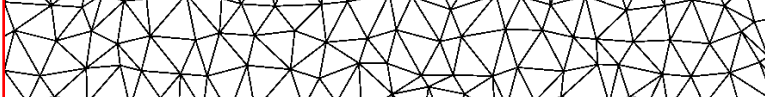

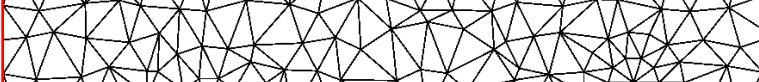

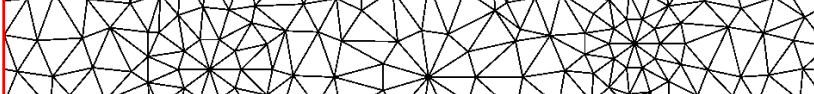

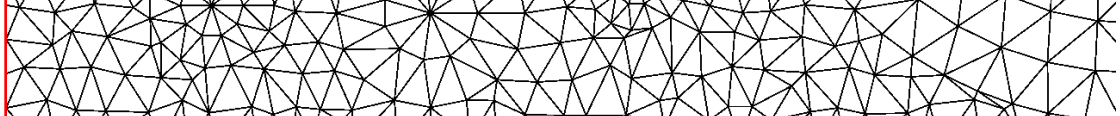

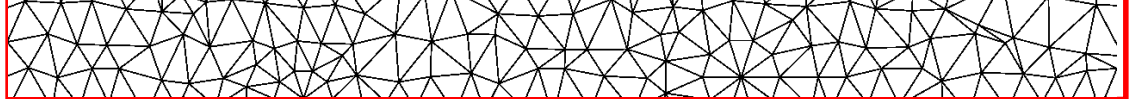

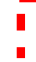

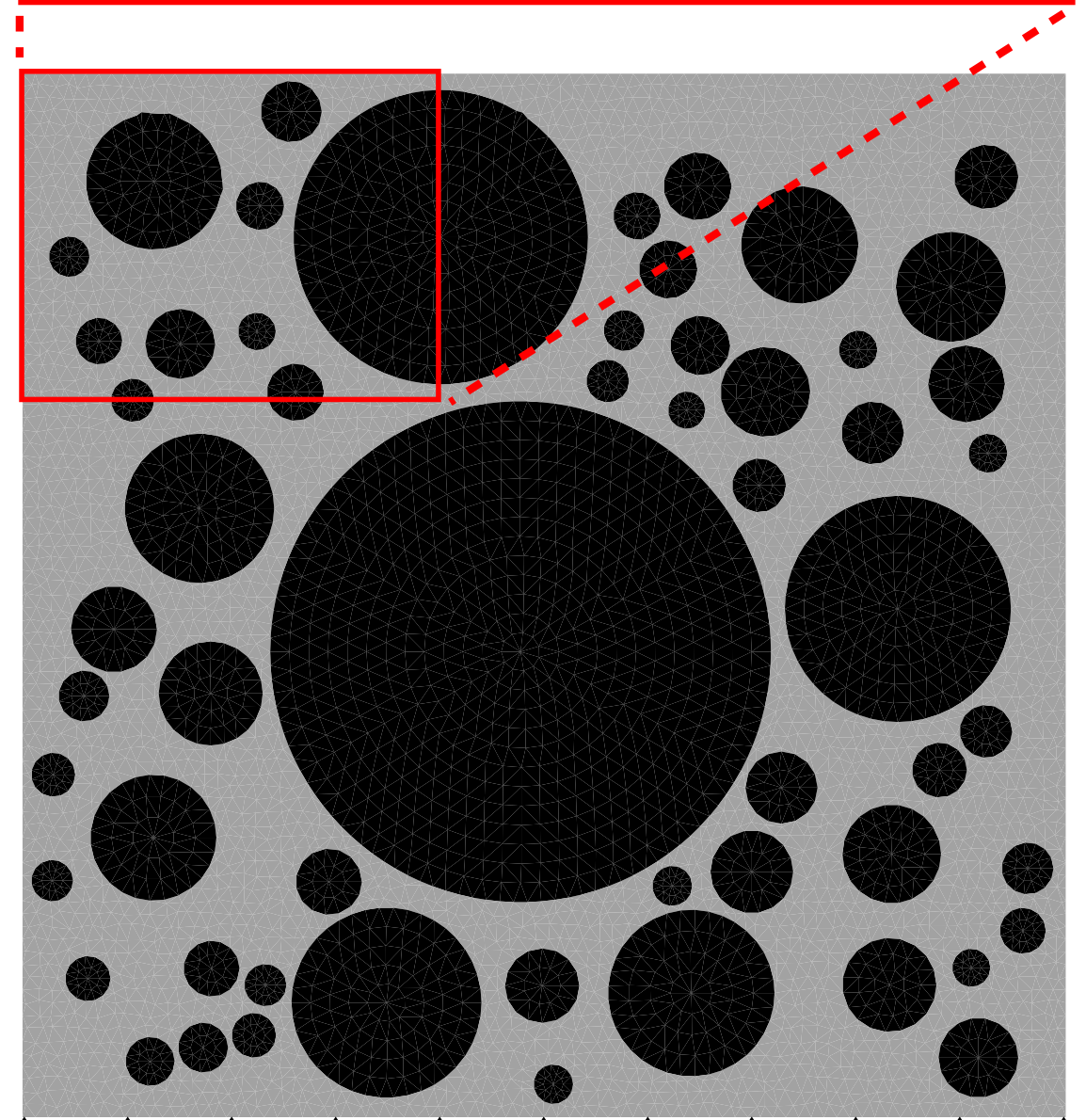

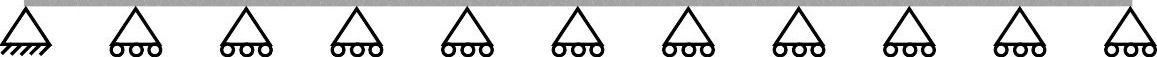


Recoverable Non-Recoverable Drying shrinkage creep creep

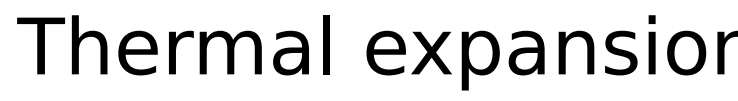

$\mathbb{E} / \tau$

$\mathbb{C}$

M

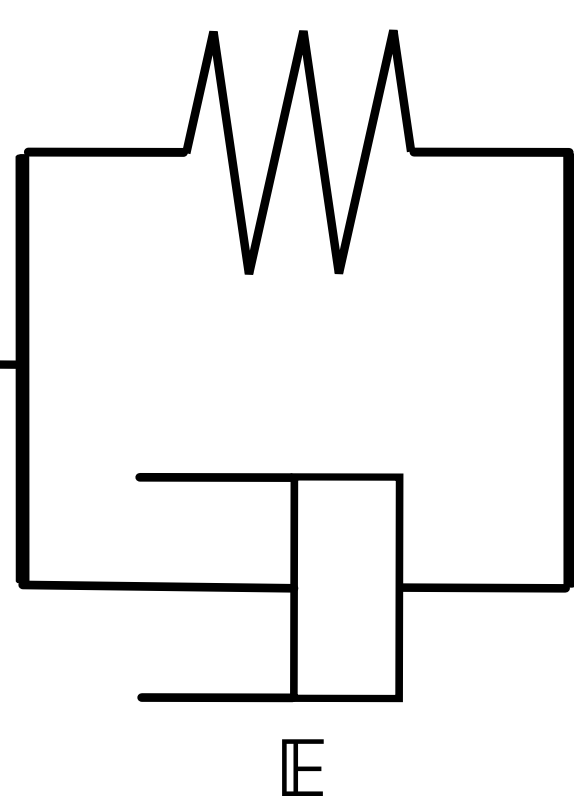

$\varepsilon(\mathrm{T}, \mathrm{h})$

$\mathbb{E}(1+\mathrm{t} / \tau)$

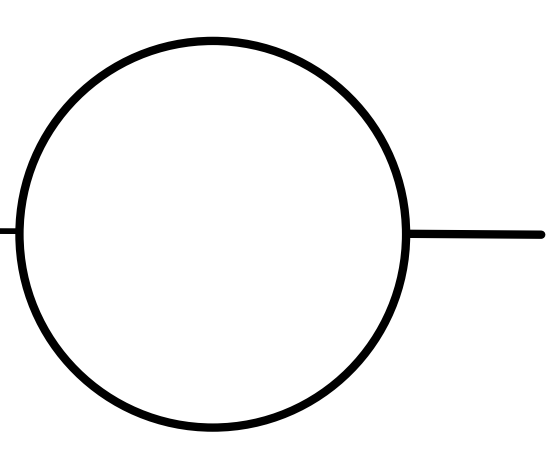




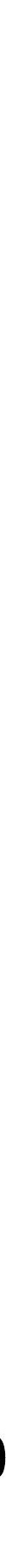


$\multimap$ OPC concrete

$[\mathrm{E}=50 \mathrm{GPa}, \eta=58 \mathrm{GPa} . \mathrm{d}, \boldsymbol{\tau}=2 \mathrm{~d}]$

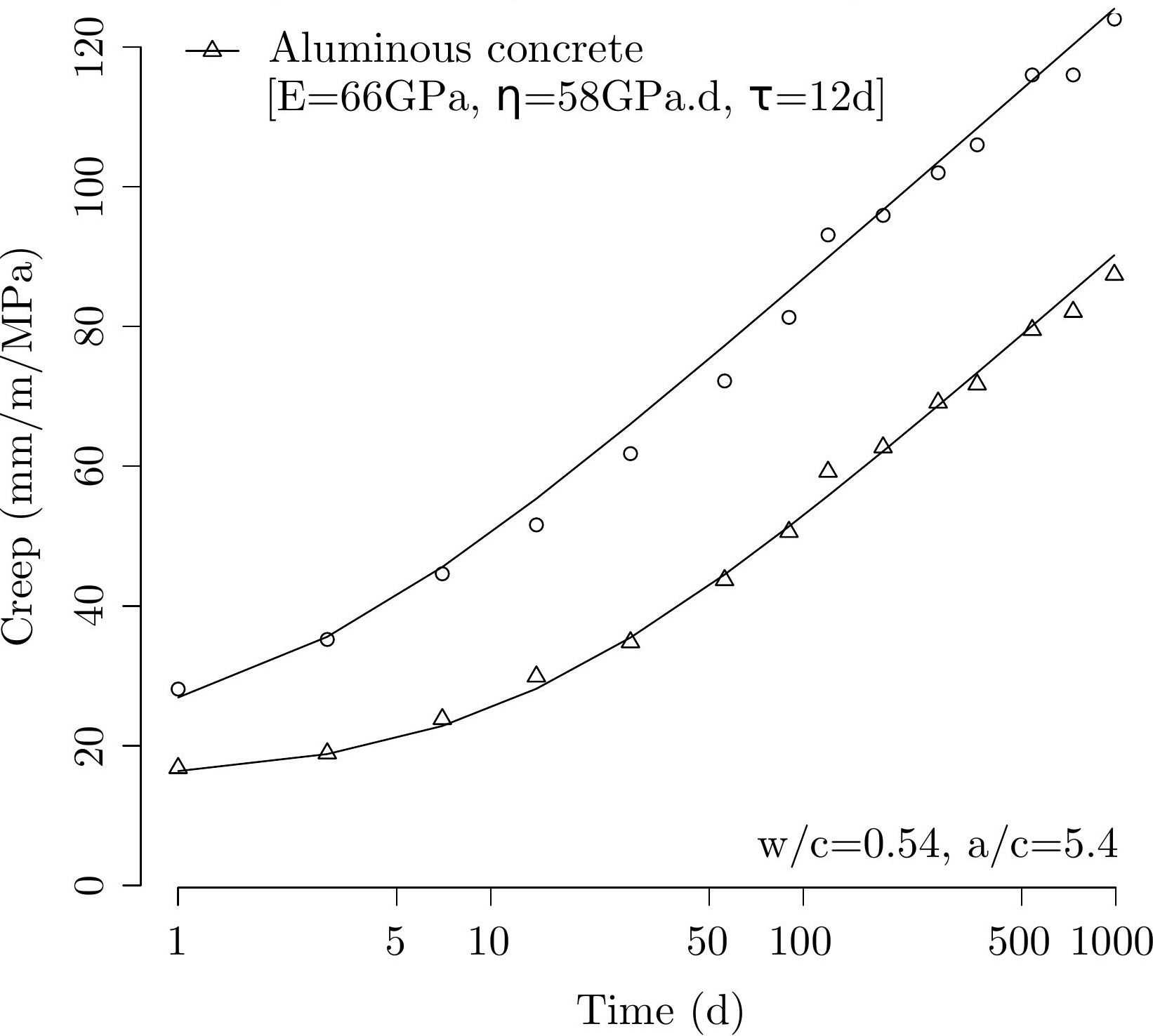




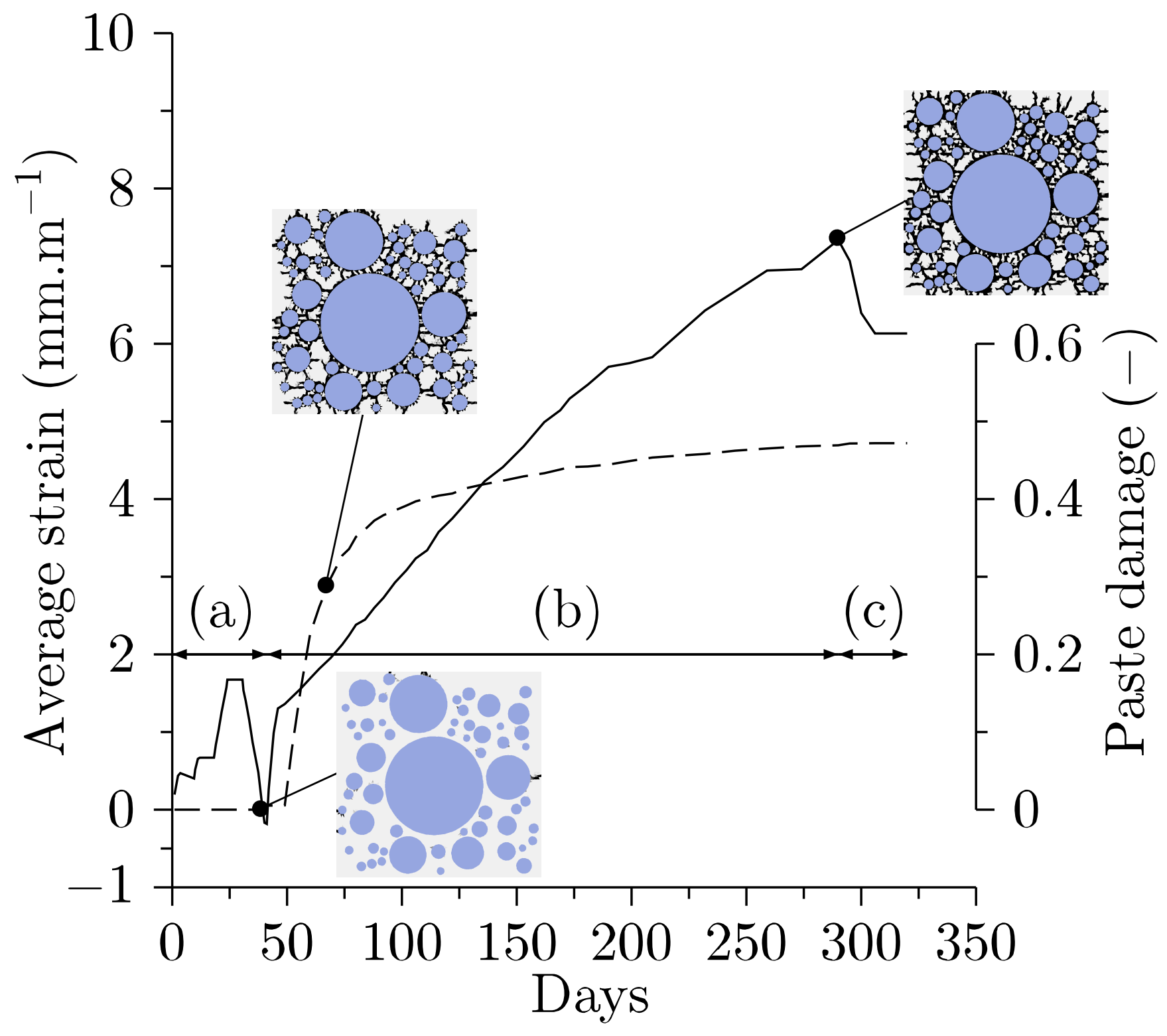




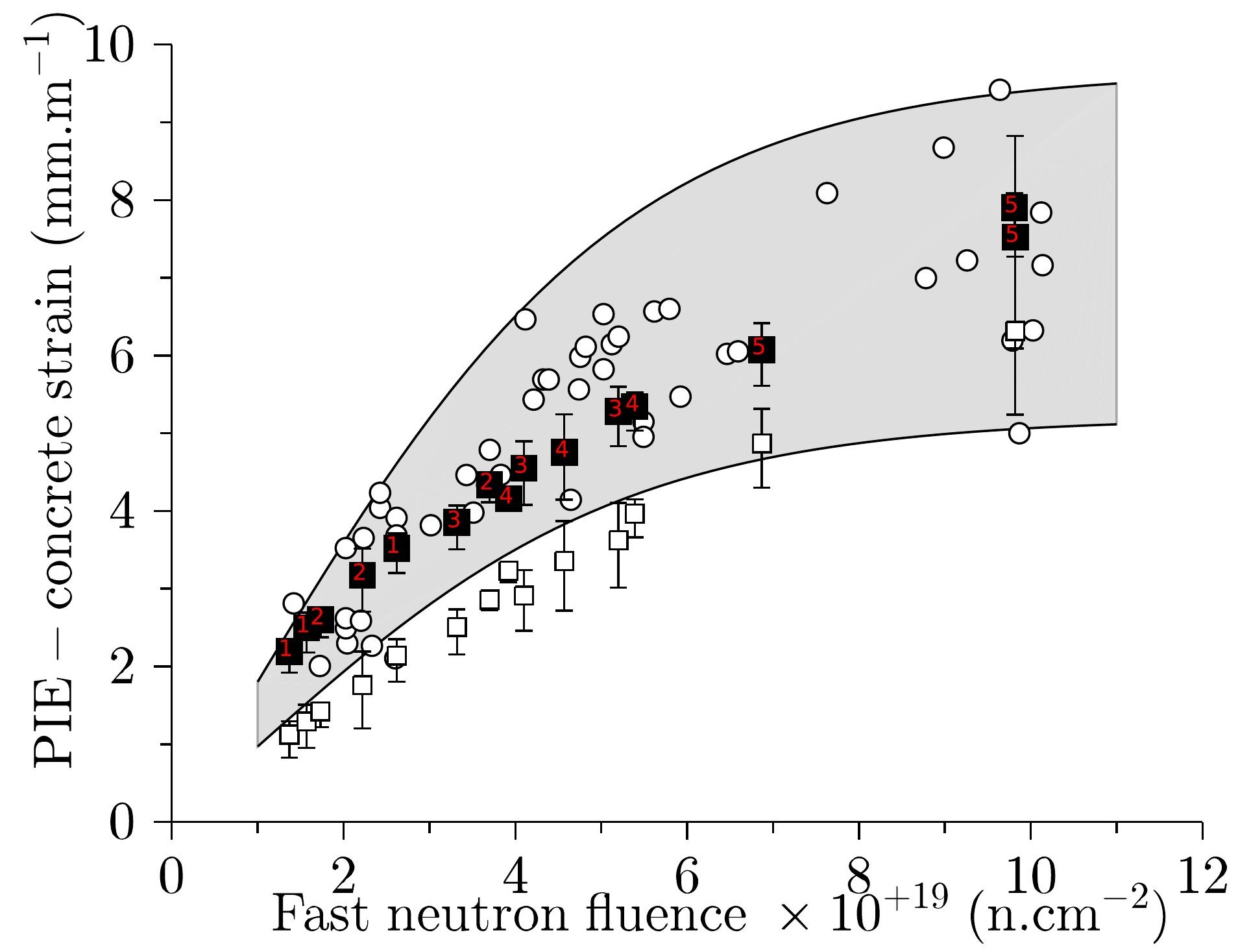




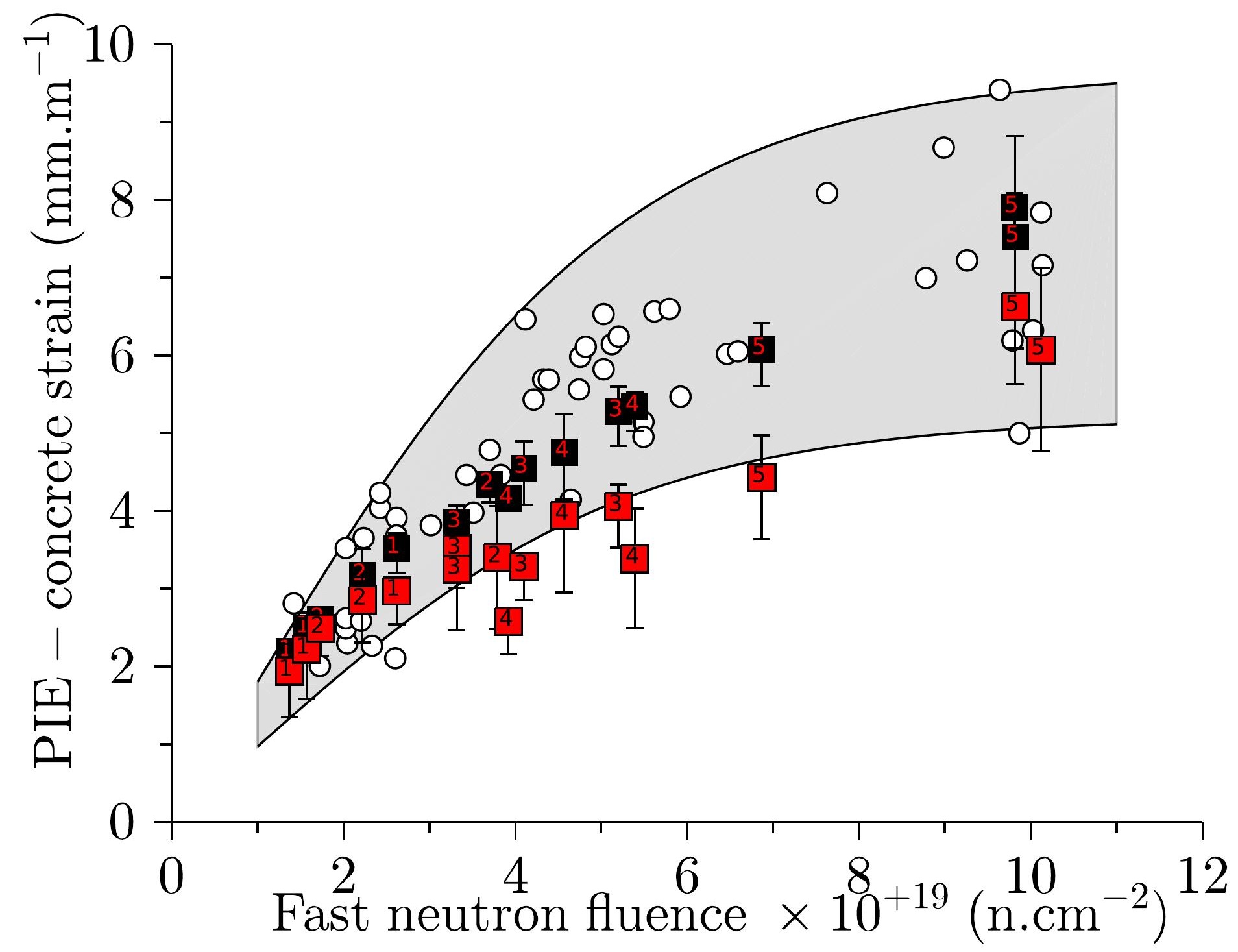




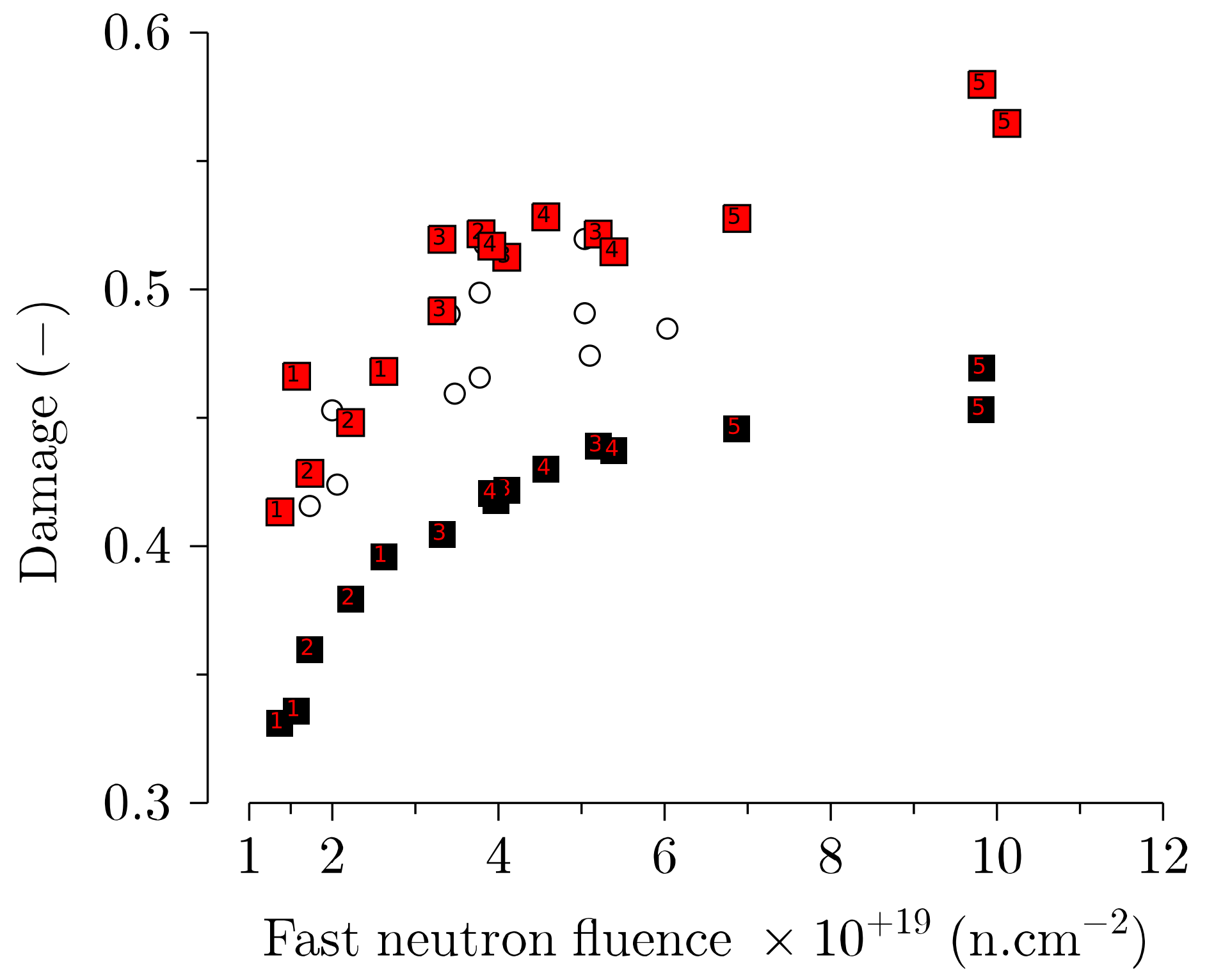




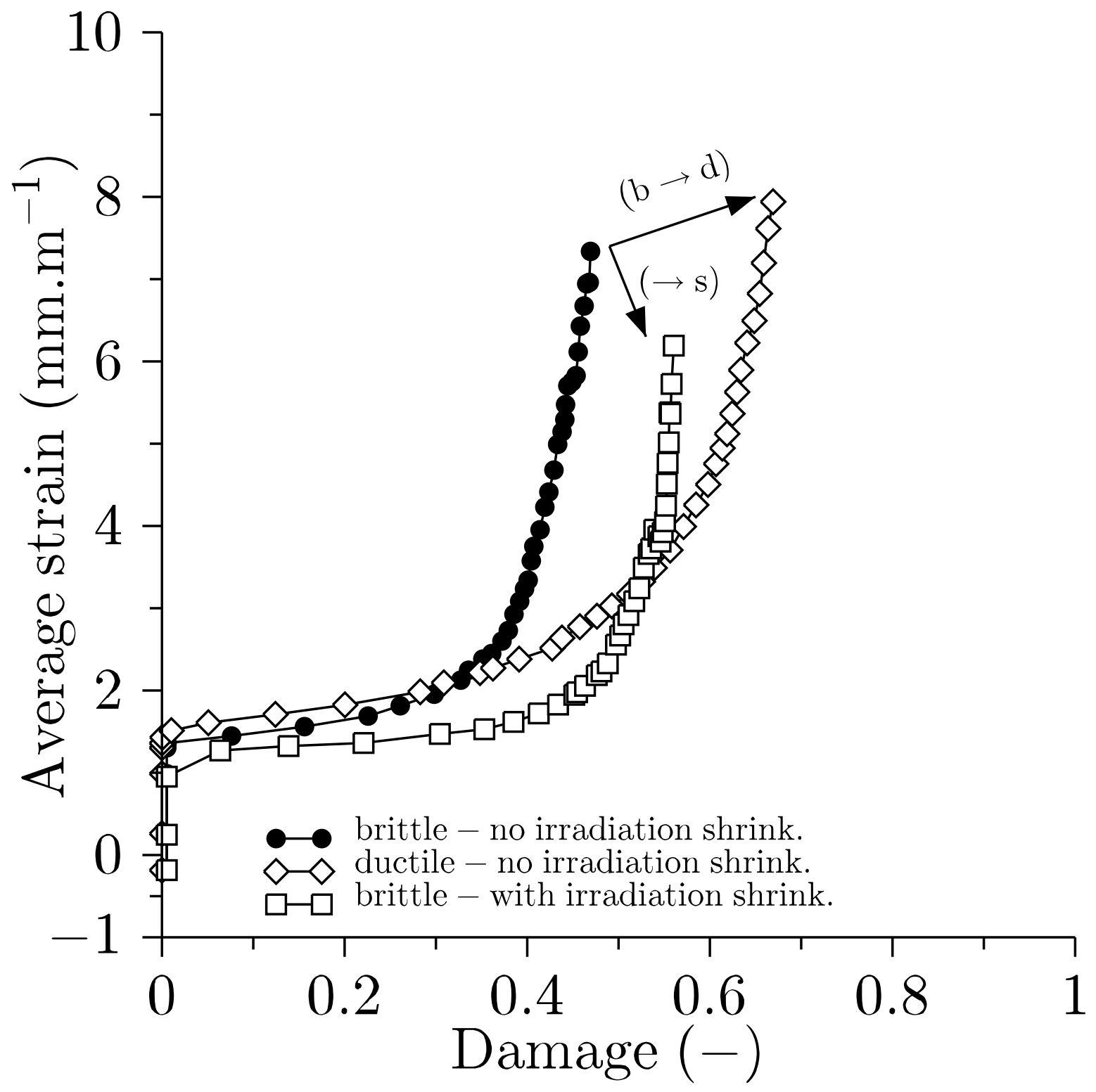


LaTeX Source Files
Click here to download LaTeX Source Files: IrradiatedConcreteORNLCTU.tex

LaTeX Source Files
Click here to download LaTeX Source Files: IrradiatedConcreteORNLCTU.tex

Click here to download LaTeX Source Files: IrradiatedConcreteonNLCTU.tex

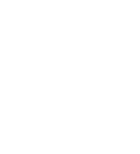
. (1) (1) (1) (1) (1) . . . (1) (1) . 列

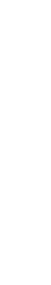

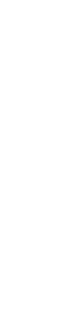
n

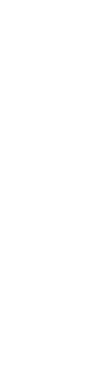
.

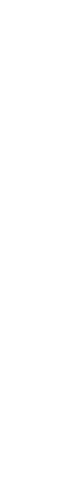

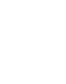
更

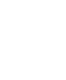
更 更 更 更 . 